NBER WORKING PAPER SERIES

\title{
PROJECTING THE EFFECT OF CHANGES IN SMOKING AND OBESITY ON FUTURE LIFE EXPECTANCY IN THE UNITED STATES
}

\author{
Samuel H. Preston \\ Andrew Stokes \\ Neil K. Mehta \\ Bochen Cao \\ Working Paper 18407 \\ http://www.nber.org/papers/w18407 \\ NATIONAL BUREAU OF ECONOMIC RESEARCH \\ 1050 Massachusetts Avenue \\ Cambridge, MA 02138 \\ September 2012
}

This research was supported by the U.S. Social Security Administration through grant \#5RRC08098400-04-00 to the National Bureau of Economic Research as part of the SSA Retirement Research Consortium. Additional funding was received from National Institute of Aging grant R01 AG04021. The findings and conclusions expressed are solely those of the authors and do not represent the views of SSA, any agency of the Federal Government, or the National Bureau of Economic Research. We are grateful to Christopher Ruhm, Andrew Fenelon, and Douglas Ewbank for their comments and suggestions.

NBER working papers are circulated for discussion and comment purposes. They have not been peerreviewed or been subject to the review by the NBER Board of Directors that accompanies official NBER publications.

(C) 2012 by Samuel H. Preston, Andrew Stokes, Neil K. Mehta, and Bochen Cao. All rights reserved. Short sections of text, not to exceed two paragraphs, may be quoted without explicit permission provided that full credit, including $\odot$ notice, is given to the source. 
Projecting the Effect of Changes in Smoking and Obesity on Future Life Expectancy in the United States

Samuel H. Preston, Andrew Stokes, Neil K. Mehta, and Bochen Cao

NBER Working Paper No. 18407

September 2012

JEL No. I0,I1,I12,I18,J1,J11,J18

\begin{abstract}
We project the effects of declining smoking and increasing obesity on mortality in the United States over the period 2010-2040. Data on cohort behavioral histories are integrated into these projections. Future distributions of body mass indices are projected using transition matrices applied to the initial distribution in 2010. In addition to projections of current obesity, we project distributions of obesity when cohorts were age 25 . To these distributions we apply death rates by current and age- 25 obesity status observed in the National Health and Nutrition Examination Survey, 1988-2006. Projections of the effects of smoking are based on observed relations between cohort smoking patterns and cohort death rates from lung cancer. We find that both changes in smoking and in obesity are expected to have large effects on mortality. For males, the reductions in smoking have larger effects than the rise in obesity throughout the projection period. By 2040, male life expectancy at age 40 is expected to have gained 0.92 years from the combined effects. Among women, however, the two sets of effects largely offset one another throughout the projection period, with a small gain of 0.26 years expected by 2040 .
\end{abstract}

Samuel H. Preston

3RSXDURQ6 6WHH\&HQMU

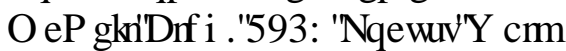

University of Pennsylvania

Philadelphia, PA 19104

and NBER

spreston@sas.upenn.edu

Andrew Stokes

Population Studies Center

McNeil Bldg, 3718 Locust Walk

University of Pennsylvania

Philadelphia, PA 19104

astokes@sas.upenn.edu
Neil K. Mehta

Emory University

1518 Clifton Road

CNR 7035

Atlanta, GA 30322

nkmehta@emory.edu

Bochen Cao

Population Studies Center

McNeil Bldg, 3718 Locust Walk

University of Pennsylvania

Philadelphia, PA 19104

caob@sas.upenn.edu 
A wide variety of personal behaviors affect an individual's health. In the aggregate, these behaviors affect the health of populations. The two behaviors that have been singled out as especially damaging to the health of the US population are smoking and the combinations of diet and physical activity that produce obesity. Estimates by the Centers for Disease Control suggest that $18 \%$ of deaths in the US in 2000 were attributable to smoking and $15-17 \%$ to obesity (Mokdad et al., 2004, Mokdad et al., 2005).

Uncertainty about the future impact of these behaviors is a central component of the uncertainty surrounding projections of future mortality (Technical Panel, 2011). And according to simulations by the Office of the Actuary, the 75-year actuarial balance of the Social Security program is more sensitive to variation in future mortality rates than it is to any other demographic or economic parameter except real wages (Trustees 2012: Appendix C). A reliable projection of the effects of these two behaviors on future life expectancy would contribute to a better understanding of the fiscal future of the United States (Soneji and King 2012).

Like most risk factors for chronic disease, smoking and obesity have effects on health that are realized over an extended period of time. Lags in the relationships between behaviors and health outcomes provide valuable information about the future of mortality, since some of the determinants of future levels may have already revealed themselves.

In this paper, we take advantage of recent observations on trends in smoking and obesity, and the relationship of those variables to mortality, to project US mortality at ages 40+ to 2040 . An earlier effort to model these effects used a two-part method of extrapolating changes in current behavior and applying mortality risks associated with those behaviors (Stewart et al. 2009). Our approach adds an additional dimension of behavioral history to the projection, allowing mortality rates to be a function not only of current behaviors but also of past behaviors.

\section{A. Background}

It is well known that the prevalence of obesity has been rising in the United States while cigarette smoking has declined. Figure 1 present time trends in the prevalence of obesity and the mean number of daily cigarettes smoked per adult.

Just as the behaviors themselves have been changing, so have the mortality risks associated with them. The National Health and Nutrition Examination Surveys (NHANES) and 
the National Health Interview Surveys (NHIS) have been tracing surveyed individuals into the National Death Index since 1971 and 1986, respectively. Relative to earlier observations, individuals surveyed in more recent years have exhibited lower mortality risks associated with obesity (Mehta and Chang 2011) and higher risks associated with smoking (Mehta and Preston 2011). The rise in smoking risks continues a trend dating back to the 1960's that was documented in very large prospective studies conducted by the American Cancer Society (Thun and Heath 1997). These changes in relative risks have occasioned upward revisions in the estimated number of US deaths attributed to smoking (Rostron 2011) and downward revisions in the number of deaths attributed to obesity (Flegal, et al. 2007; Mehta and Chang 2009).

One factor that links behavioral changes with changes in relative risk is the duration of time that individuals have spent in unhealthy states. Thun et al. (1997: Appendix 17) find that, between 1959 and 1982, the mean duration of smoking among male current smokers rose modestly but among female current smokers aged 60-79 it rose by 9-12 years. Mehta and Preston (2011) find that these trends have continued but at a slower pace; they find a 1.0 year increase in mean duration of smoking among female smokers aged 50-74 between 1987-92 and 1997-2003, and a very small increase during this period occurring among men.

Meanwhile, declines in the duration of obesity have occurred among the obese. We compared data from NHANES 3 (1988-1994) and NHANES Continuous (2003-2004) surveys that contain three lifetime observations of body mass index (BMI), beginning at age 25 and extending to a final observation in the age interval 50-74. We estimated that among individuals aged 50-74 who were obese, the mean duration of obesity declined from 17.6 years in 1990 to 14.3 years in 2004 (Preston et al., 2012). This reduction in the mean duration of obesity among the obese is likely to be a product of the rapid recent inflow of people into this category.

So smoking and obesity present mirror images. The prevalence of obesity has increased, the mean duration of obesity among the obese has decreased, and so has the mortality risk associated with obesity. On the other hand, the prevalence of smoking has declined, the mean duration of smoking among smokers has increased, and so has the mortality risk associated with smoking. At a minimum, these results suggest that "history matters" in translating behaviors into mortality risks. This conclusion is supported by direct evidence in prospective cohort studies that the history of obesity, in addition to baseline obesity, is an important risk factor in mortality 
(Preston, Mehta, and Stokes 2012; Abdullah et al. 2011). Duration of smoking is also strongly related to mortality risks among current smokers (Mehta and Preston, 2012).

\section{B. Overview of Analytic Strategy}

Our goal is to estimate the effect of changes in the lifetime distributions of smoking and obesity on future death rates. In the case of obesity, we project obesity distributions that contain past as well as current levels of obesity for cohorts in the future. We then apply multidimensional mortality risks that recognize the impact of past as well as current levels of obesity on mortality. These risks are derived from relatively recent experience observed in NHANES.

In the case of smoking, we take advantage of the fact that there is a clear marker of the impact of smoking histories on mortality: death rates from lung cancer. Smoking is the overwhelming factor accounting for variation in lung cancer mortality. Among US men aged 30 and older in 2005, it is estimated that $90 \%$ of lung cancer deaths are attributable to smoking; for females, the figure is $84-85 \%$ (Oza, et al. 2011). Consistent with a major role for behavioral histories, death rates from lung cancer are organized on a cohort basis in the United States (Preston and Wang 2006). This feature permits the identification of "cohort effects" that can be projected into the future as cohorts age. The final step in our analysis is translating projected death rates from lung cancer into all-cause mortality rates, using statistical relations that have been developed between smoking's impact on lung cancer and its impact on all-cause mortality.

In the case of both smoking and obesity, our principal goal is to project the proportionate effect of changes in these behaviors on age-specific death rates. Our comparison schedule is simply the age-specific death rates at baseline, which reflect the behavioral histories that have been accumulated at that point. We are not attempting to project all determinants of mortality into the future; instead, we attempt to isolate the impact of two behavioral changes. If there are other sources of future change in mortality, we are assuming that the effects of behavioral change will be independent of them. ${ }^{1}$

\section{Projecting the Effects of Changes in Obesity}

\footnotetext{
${ }^{1}$ Soneji and King (2012) incorporate data on smoking and obesity into their Bayesian projections of future mortality in the US, but "do not attempt to estimate causal effects of specific risk factors" (p. 1046).
} 
We project the effects of past and future changes in obesity in three stages. First, we project obesity distributions from 2010 to 2040 using sex and age-specific BMI transition matrices derived from NHANES. We use a combination of the five 10-year transition matrices that were reported in NHANES between 1999 and 2008. We present evidence below that BMI transition matrices have been nearly constant for the past 18 years and we maintain the assumption of constancy into the future. Even though the transition matrix is assumed to be constant, large increases in obesity are projected. Second, we project the distribution of age-25 BMI from 2010 to 2040. That is, for each age group through 2040, we estimate the distribution of BMI when the cohort occupying that age group was aged 25. Third, we apply death rates drawn from NHANES to the distribution of current BMI and BMI at age 25.

\section{C.1 Forecasting the future distribution of obesity}

Previous forecasts of obesity can be classified into three categories. The most common procedure has involved extrapolation of past trends in the prevalence of obesity, most often by using a linear model (Wang et al. 2008; Ruhm 2007; Stewart et al. 2009). Linear models do not recognize that the proportion of the population at risk of becoming obese declines as the proportion obese rises. A recent analysis using linear extrapolation reached the implausible conclusion that all Americans would become obese by the year 2048 (Wang et al. 2008).

A second approach involves forecasting future BMI levels on the basis of a predictive regression model and extrapolations of covariate series (Finkelstein et al. 2012). A wide array of factors associated with obesity have been identified as important influences on caloric imbalance: employment, physical activity at work, food prices, the prevalence of restaurants, cigarette smoking, cigarette prices and taxes, food stamp receipt, and urbanization (Baum and Chou 2011 provide a good review). The only study that has used such an approach to projection built a predictive model using state-level covariates believed to be associated with or causative of obesity. Covariates included alcohol and gas prices, the price of healthy relative to unhealthy foods, the unemployment rate and state indicator variables. The main limitations of this approach are that selection of covariates can be arbitrary and projection of covariate series often involves as much uncertainty as projecting obesity directly. Additionally, the $\mathrm{R}^{2}$ value of the predictive 
regression model was 0.06 (Finkelstein et al. 2012), which raises concerns regarding the extent to which the model captured the relevant dynamics.

We adopt a third approach, Markov modeling (Basu 2010). Markov models simulate flows of individuals through mutually exclusive states. Individuals are arrayed by BMI at baseline (time 1) and are subjected to a set of probabilities of being found in various BMI states at some future date (time 2), dependent on what state they were in at time 1. A set of transition probabilities can also be applied to project the distribution from time 2 to time 3 . Relative to extrapolation, this approach does not require specification of a functional form. A second advantage is that such models are able to recognize what is empirically observable, that an individual's BMI level at time 2 depends upon his or her BMI level at time 1. If those functions were changing wildly from period to period, they would provide an unstable basis for projection. However, we will show that the 10-year pattern of weight transitions has become relatively stable, and we project that stability into the future.

To develop transition probabilities, we use data from NHANES, a series of nationally representative surveys of the non-institutionalized U.S. population conducted by the National Center for Health Statistics (NCHS). The survey includes an examination component in which extensive medical data, including height and weight, are collected by trained nurses in mobile clinics or in-home visits. Certain NHANES surveys ask respondents to recall their weight 10years prior to the survey. ${ }^{2}$ We combined data on recall weight with current height to estimate 'recall BMI' in each period. To reduce bias that may result from inaccurate recall of past weight, we applied an individual-level correction factor based on the proportionate error between measured and self-reported BMI at baseline (Flegal et al. 1995). We used data on measured height and weight at the time of the survey to calculate 'current BMI'. The combination of corrected recall BMI and current BMI served as the data inputs for estimating 10-year transition probabilities. We use four BMI categories: Normal (BMI < 25.0), Overweight (25.0 to 29.9), Obese I (30.0 to 34.9) and Obese II-III (35.0+).

We used ordered logistic regressions models to estimate age- and sex-specific transition probabilities across BMI categories in each of three decadal periods between 1980 and 2010 (i.e., 1980-1990, 1990-2000, 2000-2010). A key question is how well these transition matrices predict changes in obesity that have actually occurred. Appendix A is addressed to this issue. We show

\footnotetext{
${ }^{2}$ These data are available for ages 35 and above, so we are limited to modeling transitions beginning at age 25 .
} 
there that the transition matrices are highly effective in projecting the BMI distributions observed in various NHANES from the beginning to the end of each projection period.

The actual transition matrices used in this exercise, denoted by $\mathrm{M}$, are shown in Table 1A for these three periods. Table 1B shows the changes in transition probabilities in each cell between the two successive matrices. The changes from $\mathbf{M}_{80-90}$ to $\mathbf{M}_{90-00}$ are large and systematic. The probability of moving up in weight class was significantly higher during 19902000 than in 1980-90. Even the highest weight class, from which no upward movement is possible, contributed to the upsurge in obesity by virtue of a significant increase in the probability of remaining if one started there.

In contrast, the changes between $\mathrm{M}_{90-00}$ and $\mathrm{M}_{98-08}$ were small. Only 1 of the 16 cells in the transition matrix showed a significant change in the transition probability during this period. On the basis of the relative stabilization of the BMI transition matrix over the past two decades, we generate a transition matrix combining data from five NHANES surveys from 1999 to 2008 and assume that this matrix is constant over the three decades starting in 2010. That matrix is presented in Table 2. The implication of this assumption of constancy is that the multitude of processes that produce weight change would operate with the same intensity in the future as they did in the recent past.

To project the BMI distribution after 2010, we begin with initial population counts in the 2010 continuous NHANES cross-classified into 96 categories according to sex, five-year age group (25-29 to 80-84) and measured BMI category (normal, overweight, obese class I and obese class II). Sample weights were incorporated so that counts are representative of the US population in that period. In each round of the projection, the first step was to survive members of the population forward 10 years using age, sex, and BMI-specific life tables drawn from pooled NHANES III and NHANES Continuous 1999-2004 cohorts linked to deaths in the National Death Index through 2006. A discrete hazards model on a person-month file was employed to generate the underlying risks.

In the second step, sex, age and BMI-specific transition probabilities are applied to surviving members of the population. Each iteration of the projection produced new population counts which serve as the initial counts for the next iteration of the projection. A new cohort of 
25-34 year olds is assumed to enter the population each decade. The distribution of BMI in these cohorts is predicted through extrapolation of the historical trend. ${ }^{3}$

Figure 2 presents the results of these projections for men and women. By 2040, 47\% of men and $51 \%$ of women are projected to be obese. Some deceleration in the rate of increase in obesity is evident with the passage of time, in contrast to linear extrapolations. Alarmingly, however, the morbidly obese (BMI>35.0) increase as a proportion of the obese for both males and females, to the point where they constitute a majority of obese women by 2020 and thereafter.

\section{C.2) Forecasting the future distribution of Age-25 BMI}

We project age-25 BMI levels for all cohorts who will be aged 25-84 at any time between 2010 and 2040. We begin with initial population counts in 2005 arrayed by sex, age and BMI at age 25. These are derived from NHANES continuous waves 2003-2006. BMI at age 25 is calculated by combining self-reported weight at age 25 with measured height at baseline for individuals less than 50 years of age and by combining self-reported weight at age 25 with selfreported height at age 25 for individuals 50 years of age and above. We begin in 2005 rather than 2010 because retrospective data on are not available in the latter year. We then survive the initial distribution forward in five-year intervals using sex, age and age-25 BMI specific life tables. Prior to estimating the initial population distribution and life tables, we applied an individualspecific correction factor to reported age $25 \mathrm{BMI}$ to account for potential errors in reporting. As above, this correction factor was calculated as the proportionate error between measured and self-reported BMI at baseline. Details may be found in Appendix B.

\section{C.3) Estimating death rates by category of BMI}

Data for the mortality analysis are derived by pooling the NHANES III (1988-1994) and NHANES Continuous 1999-2004 surveys. BMI at baseline is calculated using measured data on

\footnotetext{
${ }^{3}$ We estimate a historical series for ages 25-34 using measured data on height and weight from NHANES continuous waves 1999-2010. We regress the proportion in each BMI category on the logarithm of time (years since 1970), an indicator for sex as well as an interaction between the two and use the parameters of the model to predict the proportions in each category of BMI for each sex in 2020, 2030 and 2040.
} 
height and weight. For purposes of calculating BMI at age 25, measured height at baseline is used for all individuals because self-reported height at age 25 among adults ages 50 and above was not available in NHANES III. Weight at age 25 is corrected by the algorithm described above. A discrete hazard model is used on a person-month file. Respondents enter the risk set two years after they are surveyed, a delay designed to reduce potential confounding from illnessrelated weight loss. Information on deaths is available through December 31, 2006. There were 2976 deaths of 21,554 respondents.

Our BMI categories at age 25 are overweight (BMI 25.0 to $<30.0$ ), obese $(\geq 30.0)$, and other ( $<25.0)$. At baseline, the categories are obese I $(30.0$ to $<35.0)$, obese II/III $(\geq 35.0)$, and other $(<30.0)$. The main model includes corrected age-25 and baseline BMI categories, age attained over follow-up (years), sex, race/ethnicity (white, black, Hispanic, other), educational attainment (< high school, high school degree/GED, some college, college graduate), and smoking status at baseline (current, former, never). We include interaction terms between linear attained age (measured from age 35) and the two baseline obese categories because of strong evidence that the relative risk of death among obese individuals declines with age (Prospective Studies Collaboration 2009). Models are estimated on a sample of attained ages 40-84. NCHSsupplied survey weights and design elements (strata and primary sampling units) are used.

Coefficients are shown in Appendix Table B1. Weight at age 25 as well as baseline weight categories are related to the risk of death in the expected direction. Three of the four BMI variables are significant at $5 \%$. Age interactions with baseline obesity are negative, as expected, and are retained in predictions.

\section{C.4) Results}

The combined effect of the projected changes in BMI, including age-25 overweight and obesity, and the estimated mortality risks are shown in Figure 3. For both males and females, the effect of changes in BMI is expected to increase over time. By 2040, the changes are expected to raise death rates in the age range of $40-84$ by $0.6 \%-13 \%$ for males and by $0.5 \%-20 \%$ for females.

We have converted the projected sets of proportionate changes in age-specific death rates into estimates of their effect on a summary measure, life expectancy at age 40, e(40). Appendix $\mathrm{C}$ describes the procedures used to translate our estimates of age-specific death rate changes into 
their effects on life expectancy. When converted into estimates of the effects on life expectancy at age 40, Table 3 shows that the decline in life expectancy (mean, males and females) is 0.22 years by 2020, 0.44 years by 2030, and 0.63 years by 2030 .

These estimated effects are smaller than those estimated by Stewart et al. (2009), who project a loss of 1.02 years in life expectancy between 2005 and 2020 as a result of increases in obesity. There are probably several reasons for this disparity. First, their linear extrapolation of BMI proportions produced a somewhat faster increase in obesity than our use of BMI transition matrices. Second, Stewart et al. used NHANES mortality rates by obesity status for the period beginning in 1971, whereas our mortality rates are derived from a period beginning in 1988. As noted earlier, the mortality risks associated with obesity have declined in NHANES. On the other hand, unlike Stewart et al. we have introduced historical data on BMI at age 25. We show below that our estimated effects of obesity increases on life expectancy would have been lower had we not incorporated this information.

\section{Projecting the Effects of Changes in Smoking}

The risk of death from smoking is clearly a function of a multitude of smoking-related behaviors, including the number of cigarettes smoked per day, the degree of inhalation, the filtration and tar content of the cigarette, and how each of these (and other) components of a smoking profile have developed over a lifetime. Historical information is critically important because of a long lag between smoking behavior and its effects on mortality. A single crosssectional indicator of smoking prevalence cannot effectively capture these many dimensions. Prevalence-based estimates of smoking risks are also affected by imprecise classification of smoking status among participants. For example, the largest prospective study of smoking risks, the Cancer Prevention Study II (CPS II) included among "lifetime non-smokers" persons who had smoked but who had not reported themselves as smoking daily for at least a year (Lestikow, 2008).

Fortunately, there is another indicator of the health effects of smoking that comprehends the many dimensions of smoking: the death rate from lung cancer. As noted above, smoking is the overwhelming risk factor in death from lung cancer, with $90 \%$ of male and $84-85 \%$ of female lung cancer deaths in the US attributable to smoking (Oza et al. 2011). Because of the 
cumulative and delayed impact of smoking on lung cancer mortality, lung cancer exhibits prominent "cohort effects"; rates of death from lung cancer are systematically arrayed by birth cohort rather than by period. Figure 4A shows male death rates from lung cancer in the United States in various birth cohorts. Clearly, there is a near parallelism among these rates on a log scale, implying that the sequence of death rates for one cohort is nearly a constant multiple of the death rates for another cohort. Figure 4B shows that this parallelism is missing when data are arrayed by period rather than by cohort. Similar cohort effects attributable to cohort smoking patterns have also been observed in Europe and Japan (Janssen and Kunst 2005; Yamaguchi et al. 2000).

Although lung cancer mortality serves as an excellent marker of the health effects of smoking, lung cancer does not account for a majority of deaths attributable to smoking. Cardiovascular diseases, other cancers, and chronic obstructive pulmonary diseases (COPD, which includes bronchitis and emphysema) also make large contributions. Two methods have been developed to connect smoking-related mortality from lung cancer to smoking-related mortality from other causes of death. Peto et al. (1992) translate observed lung cancer death rates into an estimate of smoking "prevalence" by referring to the difference between lung cancer death rates for smokers and non-smokers in CPS-II. This estimate of smoking prevalence is then used to estimate the risk attributable to smoking for other smoking-related causes of death by employing the cause-specific relative risks for smokers versus non-smokers from CPS-II.

The second method also uses lung cancer mortality as the basic indicator of the damage caused by smoking (Preston, Glei, and Wilmoth 2011). However, rather than relying on the relative risks from CPS-II or any other study, it estimates the macro-level statistical association between lung cancer mortality and mortality from all other causes of death in a dataset of 21 countries covering the period 1950 to 2006. In addition to lung cancer mortality, the statistical model includes age, sex, period, and country effects as well as interactions among them. This approach is motivated by the expectation that lung cancer mortality is a reliable indicator of the damage from smoking and that such damage has left a sufficiently vivid imprint on other causes of death that it is identifiable in country-level data. The strong statistical relations that emerge are consistent with that expectation.

The two methods of translating lung cancer mortality into all-cause mortality give very similar results. The proportion of deaths attributable to smoking that are estimated by the two 
methods is correlated at 0.96 for males and 0.94 for females across 20 countries in 2000 (Preston, Glei, and Wilmoth 2011). Both methods implicitly assume that the pattern of lags between smoking and lung cancer death is similar to that between smoking and other causes of death. Is that assumption reasonable? Preston, Glei, and Wilmoth (2011) experimented with various lags between lung cancer mortality and mortality from other causes of death and found that a model in which the two death rates were contemporaneous (i.e., exhibited no lags) worked best (unpublished result). Oza et al. (2011) examine time-patterns of relative mortality risks of smokers from various causes of death. Relative to the lag between smoking behavior and death for lung cancer, they found the lag structure to be longer for chronic obstructive pulmonary disease (COPD) and shorter for cardiovascular diseases. Using the Peto et al. (1992) approach, the estimated number of deaths attributable to smoking differed by only $1.7 \%$ when lag structures were incorporated compared to when they weren't. Thus, it appears that the pattern of lung cancer lags is sufficiently similar to that for the aggregate of other causes of death that serious distortions do not arise from assuming that they are, on average, the same.

Our projections of the mortality effects of smoking are based on the identification of cohort effects in lung cancer mortality. Mortality levels that are unique to cohorts are obviously a convenient vehicle for projecting mortality because cohorts age with completely predictable regularity.

\section{D.1) Data for analysis of smoking effects}

Data on lung cancer deaths by age, sex, and period are drawn from annual volumes of Vital Statistics of United States for periods from 1945 through 1949, from the website of the World Health Organization/International Agency for Research on Cancer for 1950 through 1998, and from files of Underlying Cause of Death 1999-2009 on CDC WONDER Online Database for 1999-2009 (National Center for Health Statistics 2012). In this paper, lung cancer refers to cancer of lung, bronchus, trachea and pleura. The International Classification of Diseases (ICD) was used to identify lung cancer deaths. The entire study period of 65 years from 1945 to 2009 are covered by ICD from version 5 to version 10. The corresponding ICD version codes used for each individual time period are list in the table below. 


\begin{tabular}{|l|c|}
\hline Year (ICD Version) & ICD Codes \\
\hline 1933-1938 (ICD-4) & $47 b, 47 c$ \\
$1939-1948$ (ICD-5) & $47 b-47 f$ \\
1949-1957 (ICD-6) & 162,163 \\
$1958-1967$ (ICD-7A) & 162,163 \\
$1968-1978$ (ICD-8A) & 162 \\
$1979-1998$ (ICD-9) & 162 \\
$1999-2009$ (ICD-10) & C33, C34 \\
\hline
\end{tabular}

Estimates of population size and counts of deaths from all causes combined are taken from the Human Mortality Database for 1933-2007. These data for 2008 and 2009 are drawn from National Center for Health Statistics (2012). ${ }^{4}$

Data on smoking by cohort are based on a detailed reconstruction of smoking histories by Burns et al. (1998). They employed a total of 15 National Health Interview Surveys (NHIS) conducted between 1965 and 1991 to estimate cohort smoking histories. David Burns supplied us with unpublished estimates using the same methodology that incorporated data from three additional National Health Interview Surveys through 2001. We updated the series using NHIS data through 2009. We converted these data into an estimate of the average number of years spent as a current smoker before age 40. This value is derived by summing across ages between 0 and 39 the annual proportion of cohort members who were estimated to be current cigarette smokers.

For cohorts that have not reached age 40 in 2010, we estimate the future cumulative years of smoking by age 40 based on observed cumulative years smoked at younger ages. For this purpose, we use regressions predicting the mean cumulative years of smoking by age 40 with independent variables representing cumulative smoking indexes by age 35, by age 30, by age 25 , and by age 20 . We add a sex indicator and a trend variable to the regressions. Regressions are estimated on data for the 16 cohorts for which we have complete data up to age 40 . The regressions in all cases explain at least 97\% of the variance in cumulative years of smoking before age 40. For the two cohorts born after 1990, we fix the variable at its level estimated for the 1985-90 cohort. The resulting series are presented in Figure 5.

\footnotetext{
${ }^{4}$ Estimates pertaining to birth cohorts are created by organizing a data matrix in 5-year age groups and 5-year time blocs. In order to align cohort mortality data with cohort smoking data, we defined 5-year birth cohorts that were centered on birth years 1900-04, 1905-09, etc. For example, mortality rates in the birth cohort of 1905-09 were comprised of death rates at ages 30-34 in 1937-41, death rates at ages 35-39 in 1942-46, and so on. The final mortality observations for cohorts still alive consisted of death rates in 2007-09.
} 


\section{D.2) Methods for projecting the mortality effects of smoking}

Our goal is to identify how lung cancer mortality varied from cohort to cohort so that we can project these cohort effects into the future. We try two principal ways to estimate cohort effects. One is to relate lung cancer mortality to a cohort smoking variable that had proven useful in prior research on all-cause mortality (Preston and Wang 2006, Wang and Preston 2009). As noted, that variable is the mean cumulative number of years that a member of a cohort had smoked prior to age 40, designated $S(a, c)$ for cohort $\underline{\mathrm{c}}$ at age $\underline{\mathrm{a}}$. For each sex, we estimate an equation of the form

$$
\ln M(a, c)=A+B_{a} X_{a}+B_{s} \ln S(a, c),
$$

where $M(a, c)$ is the lung cancer death rate at age a in cohort $\underline{\mathrm{c}}, X_{a}$ is an indicator of age category a $\underline{a} B_{a}$ is the coefficient of age category $X_{a}$, and $B_{s}$ is the coefficient of $\ln S(a, c)$. We estimate this model using negative binomial regression on death counts on all observations at ages 40-44 to 80-84 for the period beginning in 1947. This start year was chosen because it produced the best fit to actual death rates in 2010 among all potential start years from 1937 to 1987. The coefficients of $\ln S(a, t)$ are 1.279 for males and 0.929 for females. Greater sensitivity of males than females to their respective smoking histories was also found by Wang and Preston (2006) and Preston and Wang (2009) based on all-cause mortality. It is also a common finding in prospective cohort studies, perhaps because women smokers on average consume fewer cigarettes per day, inhale less frequently, and smoke cigarettes lower in tar content (Thun et al. 1998). Age coefficients are monotonically and smoothly rising at a diminishing rate for both sexes.

The second approach is to estimate "cohort effects" as coefficients of dummy variables pertaining to various cohorts, without any reference to smoking histories. ${ }^{5}$ We estimate the parameters of a straightforward age/cohort model,

\footnotetext{
${ }^{5}$ Such an estimate could be made using an age/period/cohort model, but it is widely recognized that introducing age, cohort, and period variables into the same model creates an identification problem because of the perfect linear association between any two of these variables and the third (Feinberg and Mason 1978). Our efforts to introduce period measures into an age/cohort model were unsuccessful in the sense that they resulted in implausible cohort and period effects, presumably because of these colinearity issues. A second reason for not invoking an
} 


$$
\ln M(a, c)=A+\Sigma B_{a} X_{a}+\Sigma B_{c} X_{c}
$$

where $M(a, c)$ is the lung cancer death rate in cohort c at age a, $B_{a}$ and $B_{c}$ are the coefficients of age category a and cohort c and $X_{a}$ and $X_{c}$ are indicators of age and cohort membership.

We estimated this model using negative binomial regression on death counts. Figures $6 \mathrm{~A}$ and $6 \mathrm{~B}$ plot cohort effects estimated from equation (2) and the mean number of years of smoking before age 40 for each cohort. The two series for women obviously track one another closely for both sexes, including an upward bump for female cohorts born 1955-64. For men, both series are an inverted-U shape, although the peak of the smoking series occurs earlier than the peak cohort coefficient. We believe that Figure 6 illustrates effectively that cohort effects in lung cancer are dominated by smoking histories.

Our projections are based on equation (1), which uses the smoking series. One advantage of this approach is that we are able to observe smoking behavior for cohorts as young as age 1519. The cohort coefficients from equation (2) are not robustly estimated until age 40-44, when substantial numbers begin to die from lung cancer. Furthermore, the smoking-based analysis produces predicted death rates in 2010 that are much closer to the actual death rates in that year than the analysis using cohort coefficients, which underestimate mortality significantly for older cohorts.

To translate projected lung cancer death rates into death rates from all causes, we use the set of translation factors by age and sex drawn from Preston, Glei, and Wilmoth (2011). These are based on the relation between lung cancer mortality and mortality from other causes of death observed in a dataset from 21 countries between 1950 and 2006, representing some 9.9 billion person-years of exposure and 284 million deaths. ${ }^{6}$ Below, we explore the sensitivity of results to this choice of translation factors.

\section{D.3) Results}

age/period/cohort model is that we had no strong hypothesis about period effects on lung cancer mortality, since we considered such mortality to be primarily a function of cohort smoking histories.

${ }^{6}$ Preston, Glei, and Wilmoth do not estimate coefficients for ages below 50. We assume that the coefficients for ages 50-54 apply to ages 40-49. Since coefficients decline with age, this choice probably produces an underestimate of smoking-attributable deaths, but there are very few deaths in the age interval $40-49$, so results are scarcely affected by this assumption. 
Figure 3B presents the results of this analysis. Male age-specific death rates are expected to decline at every age throughout the projection period. The heaviest smoking male cohorts are already aged 80+ in 2010 and the impact of changes in cohort smoking patterns is to produce a steady decline in relative death rates as age and time advance. In contrast, female rates are expected to rise in the oldest age intervals during the early years as heavy-smoking cohorts replace lighter-smoking ones (cf. Figure 5). Projected male declines are larger than female declines in nearly all comparisons, reflecting the more gradual changes in cohort smoking propensities among women.

Table 3 converts the age-specific projections into estimates of the effect on life expectancy at age 40. Males show a relatively steady improvement in life expectancy over time and a total gain of 1.52 years by 2040. In contrast, female life expectancy is expected to fall from changing smoking patterns between 2010 and 2015 as the heaviest smoking cohorts move into the prime ages of dying. There is projected to be virtually no gain in female life expectancy as a result of smoking reductions between 2010 and 2020. However, female gains accelerate after 2025 as the heaviest smoking cohorts disappear. By 2040, women are projected to have gained 0.85 years in e(40) from smoking reductions.

There are two other projections of anticipated changes in mortality as a result of changing smoking patterns. Wang and Preston (2009) add a cohort smoking term to the conventional LeeCarter model of mortality change from all causes of death combined. They summarize their results in the form not of life expectancy but rather of the probability of surviving from age 50 to age 85. For the projection period 2009-2034, they estimate that reductions in smoking will increase the probability of male survival by $15.8 \%$ and of female survival by $7.2 \%$. In the present set of projections, changes in this probability between 2010 and 2035 are 13.4\% for males and $4.7 \%$ for females. Because mortality from lung cancer is a more sensitive indicator of the damage from smoking than is all-cause mortality, we believe the present estimates are more reliable.

Stewart et al. (2009) also project the effects of changes in smoking on future life expectancy by extrapolating trends in smoking distributions and applying death rates by smoking status from NHANES. They do not differentiate between the sexes. They estimate that, in a 15year projection period beginning in 2005, declines in smoking will produce a 0.31 year gain in 
life expectancy at age 18. In our 15-year projection beginning in 2010, we estimate that declines in smoking will raise life expectancy at age 40 by 0.80 years for males and 0.15 years for females, with an average gain of 0.47 years. ${ }^{7}$ While our results appear to show a faster improvement than theirs, the rate of improvement accelerates through the period. In our 10-year projection ending in 2020, the same year that the Stewart et al. projections end, our gain in life expectancy (mean, males and females) is 0.28 years compared to their 0.31 years over the preceding 15-year period. Thus, our results appear reasonably consistent with theirs over this short projection period.

\section{E. Combining obesity and smoking}

Our research design does not allow us to investigate interactions between smoking and obesity. Are the effects of changes in smoking and obesity likely to be additive and independent, as we have assumed, or might there be important interactions between them? Two types of interactions may be relevant. One refers to behavioral associations between smoking and obesity. To take the most obvious example, if smoking reduces the likelihood of being obese, then declines in smoking should be reflected in increases in the prevalence of obesity. Flegal et al. (1995) have estimated that 20\% of the increase in adult obesity between 1980 and 1990 is a result of smoking cessation during that period. Using data on two cohorts from the National Longitudinal Study of Youth, Baum and Chou (2011) estimated that only 2\% of the increase in obesity among young adults over a recent 20-year period was attributable to declines in smoking. These are not large effects, and there is no obvious reason why the relation between the prevalence of the two risk factors over the next decades would differ from that in the recent past.

The second type of interaction is interaction between the two mortality risks themselves. If the mortality risk from obesity is lower among smokers, as is sometimes claimed (Allison et al. 2001), then the projected reduction in smoking should raise the risk of death associated with obesity. However, the largest meta-analysis of cohort studies of obesity concluded: "Throughout the range $25-50 \mathrm{~kg} / \mathrm{m}^{2}$, the effects of BMI and smoking seemed to be roughly additive, rather

\footnotetext{
${ }^{7}$ Changes in life expectancy at ages 18 and 40 are highly comparable because so few years of life are lost between these ages.
} 
than multiplicative, both for vascular mortality and for all-cause mortality" (Prospective Studies Collaboration 2009: 1090).

Assuming independence between the mortality risks of obesity and smoking, we multiply the effects of changes in obesity and smoking that were presented in Figure 3. Results are shown in Figure 7. The preponderant downward slope of both sets of results when smoking and obesity are considered independently is accentuated when the effects are multiplied together. The obesity effect dominates the smoking effect below age 60, where death rates are projected to be higher than baseline throughout the projection period. Above age 60, the smoking effect is clearly dominant and produces reductions in mortality.

Table 3 summarizes these changes in the form of life expectancy at age 40. The combined effect of changes in smoking and obesity is expected to produce steady improvements in male life expectancy through 2040, with a total gain of 0.92 years by that date. On the other hand, women's life expectancy is expected to be lower as a result of the combined changes through 2030. Thus, the pattern of reductions in the female advantage in life expectancy that has been evident since 1979 is expected to continue for another two decades, at least from these sources. By 2040, life expectancy is anticipated to be 0.26 years higher for females as a result of these combined behavioral changes.

\section{F. Sensitivity Analyses}

We performed five analyses of the effect of changes in procedures on outcomes. In each case, we estimated the effect of an alternative procedure on age-specific death rates and converted those rates into estimated effects on life expectancy at age 40. Results for life expectancy at age 40 are shown in Table 4. The values in that Table are the difference between the life expectancy value produced by the alternative procedure and that produced by our main procedures. A positive value means that the alternative procedure resulted in a gain in projected life expectancy relative to the main procedure. When the alternative procedure relates to obesity, the comparison is made with the main obesity results; smoking results are compared to smoking results.

Four of the five sensitivity analyses are made with respect to obesity. These are described in detail in Appendix B. In our baseline analysis, we used retrospective data as the basis for 
projecting age-25 BMI distributions for individuals ages 25-84 in 2010-2040. Rather than using self-reported age-25 data, the first sensitivity analysis uses measured data derived from NHES I (1959-1962), NHANES I-III (1970-74, 1976-1980, 1988-1994) and continuous NHANES (19992010) as the basis for projecting future age-25 BMI distributions. Table 4 shows that results were not sensitive to whether estimates were based on measured or self-reported data on age-25 BMI. No difference between the procedures in any projection period was as large as 0.10 years, and the adjustment had consistent effects on men and women.

Second, we examine the sensitivity of results to the projected changes in current BMI at ages 25-34 as well as changes in age-25 BMI. Instead of extrapolating recent trends in the BMI distribution at these ages, in the sensitivity analysis we have assumed the distribution to remain constant at its level in 2010. Table 4 shows that this change has very little effect on results. At the peak effect, women's life expectancy would be only 0.04 years higher in 2040 if no increase were to occur in obesity at ages 25-34. Estimated mortality effects are not sensitive to assumptions about trends in levels of obesity at younger ages because so much of the dying is concentrated at older ages.

The other two changes in obesity procedures pertain to the regression equation linking mortality to BMI. To show the impact of controlling educational attainment, race/ethnicity, and smoking in the mortality estimates, we have repeated the mortality analysis for obesity without these controls, using the regression equation presented in Appendix Table B2. Table 4 shows that results are insensitive to this change in procedure: the effect on e(40) never reaches 0.06 years.

The final sensitivity analysis involving obesity examines the effect of omitting information about age-25 BMI. We re-estimate the regression equation predicting mortality based on BMI after excluding terms representing BMI at age 25. Results are presented in Appendix Table B3. Table 4 shows that including age-25 information has an important effect on results. By 2040, losses in life expectancy are 0.15 years greater for men and 0.22 years greater for women when age-25 BMI is included than when it is not. These represent increases in the impact of obesity of $25 \%$ for men and $34 \%$ for women relative to the estimated impacts when age-25 BMI is omitted. We believe that these results justify the effort to include life history information in the analysis.

The sensitivity analysis involving smoking uses an alternative set of relations between lung cancer mortality and all-cause mortality. The main results presented above are based on 
relations estimated across 21 countries from 1950 to 2006. Fenelon and Preston (2012) instead estimate coefficients relating lung cancer to all-cause mortality that are based on variations across 50 states of the US between 1996 and 2004. Coefficients that predict mortality from other causes of death on the basis of lung cancer mortality are very similar for men to those in Preston, Glei, and Wilmoth (2011) but lower for women at younger ages. ${ }^{8}$

Results in Table 4 show that the sensitivity of results is minor for the first 10 years of projection, modest for the second 10 years, and sizeable by 2040. Of the projected 1.52 years of gain in life expectancy from reductions in smoking by 2040 for males in Table 3, 0.32 years would be eliminated if the alternative relations were used. Of the 0.85 year gain for women, 0.36 years is eliminated if the alternative relations are used. The alternative results have the virtue of being based on contemporary relations in the US, but the main results are based on many more data points. We believe that the comparison of the two approaches provides a realistic picture of the degree of uncertainty in the smoking results; they are clearly less robust than the obesity results. However, using either the main approach or the alternative, declines in smoking are expected to produce substantial gains in life expectancy by 2040.

\section{G. Conclusion}

The combined effects of past and future changes in obesity and smoking are likely to result in an improvement in US life expectancy over the next 30 years. This improvement occurs because the advantages of reductions in smoking outweigh the penalty imposed by increases in obesity. Over the next decade, however, the combined effects are likely to produce only a very small improvement in mortality for the combined sexes because the heaviest smoking cohorts of American women are still in or approaching the ages of greatest vulnerability to death.

Our results differ from those of Stewart et al. (2009), who forecast that the negative survival effects of obesity would exceed the advantages of reduced smoking over the period 2005-2020. Some of the apparent difference in results is a product of the different periods of analysis. We find relatively small net effects of the two forces between 2010 and 2020; more precisely, sizable gains in life expectancy are projected for men with small losses for women. It

\footnotetext{
${ }^{8}$ Neither approach estimated a coefficient for ages 85+. Preston, Glei, and Wilmoth (2011), the source of the main analysis, used the mean coefficient at ages 70-74, 75-79, and 80-84 to apply to ages $85+$. We make this same assumption for the alternative method based on Fenelon and Preston (2012).
} 
is only in the years beyond 2020, when the advantages of reduced smoking among women start to be fully realized, that smoking gains strongly outpace obesity losses. On the other hand, some of the differences between our results and those of Stewart et al. reflect a much smaller role for obesity in the present estimates. The reduced role probably results primarily from our projection of a slower increase in obesity and our use of lower mortality risks associated with the condition. Our smoking results appear to be in reasonable accord with those of Stewart et al. over their shorter projection period.

Are the changes that we have projected large or small? One useful metric is provided by projections made by the Social Security Administration (Bell and Miller 2005). They anticipate that life expectancy at age 40 will grow between 2010 and 2040 by 2.55 years for men and 2.17 years for women. Against this backdrop, the mean of gains that we estimate from reduced smoking (1.52 years among men and 0.85 year among women) would themselves account for almost exactly half of the mean gain in life expectancy. These gains will be partially offset by the consequences of increases in obesity. As a percentage of the life expectancy increases projected by the Social Security Administration, growing obesity imposes a penalty of $29 \%$ for men and $31 \%$ for women. These two behaviors clearly exert a major influence on American mortality and warrant continued monitoring and analysis. 
$\underline{\text { References }}$

Abdullah A, Wolfe R, Stoelwinder JU, et al. 2011.The number of years lived with obesity and the risk of all-cause and cause-specific mortality. Int J Epidemiol. 2011:1-12

Allison, David B., Moonseong Heo, Kevin R. Fontaine, and Daniel J. Hoffman. 2001. "Body Weight, Body Composition, and Longevity”. Pp. 31-48 in International Textbook of Obesity. Edited by Per Bjorntorp. John Wiley \& Sons.

Basu, A., 2010. "Forecasting distribution of body mass index in the United States: is there more room for growth?" Medical decision making : an international journal of the Society for Medical Decision Making, 30(3), p.E1-E11.

Baum, Charles L. and Shin-Yi Chou. 2011. "The Socio-economic causes of obesity". National Bureau of Economic Research Working Paper 17423. Cambridge, Mass

Burns, D.M., L. Lee, L.Z. Shen, E. Gilpin, H.D. Tolley, J. Vaughn, and T.G. Shanks. 1998. "Cigarette Smoking Behavior in the United States." Pp. 13-112 in Changes in Cigarette-Related Disease Risks and Their Implication for Prevention and Control, edited by D.M. Burns, L. Garfinkel, and J. Samet. Smoking and Tobacco Control Monograph No. 8. Bethesda, MD: Cancer Control and Population Sciences, National Cancer Institute, U.S. National Institutes of Health.

Ezzati, M. and A. D. Lopez. 2003. "Estimates of Global Mortality Attributable to Smoking in 2000." Lancet 362:847-52.

Fenelon, Andrew and Samuel Preston. 2012. "Estimating Smoking-Attributable Mortality in the United States.” Demography. Forthcoming, August 2012.

Fienberg, Stephan E., and William M. Mason. 1978. "'Identification and Estimation of AgePeriod-Cohort Models in the Analysis of Discrete Archival Data.', Pp. 1-67 in Sociological Methodology, Vol. 8, edited by K.F. Schuessler. San Francisco: JosseyBass.

Finkelstein, E.A., Olga A. Khavjou, Hope Thompson, Justin G. Trogdon, Liping Pan, Bettylou Sherry, William Dietz, 2012. "Obesity and Severe Obesity Forecasts Through 2030" American Journal of Preventive Medicine. Electronic release, May. pp.1-8.

Flegal, K.M. , Richard Trioano, Elsie Pamuk, Robert Kuczmarski, and Stephen Campbell. 1995. "The Influence of Smoking Cessation on the Prevalence of Overweight in the United States". New England Journal of Medicine. 333(18): 1165-70.

Flegal, K.M. et al., 1998. Overweight and obesity in the United States: prevalence and trends, 1960-1994. International Journal of Obesity, 22(1), pp.39-47.Flegal, K.M. et al., 2012.

Flegal, Katherine M., Barry I. Graubard, David F. Williamson, Mitchell H. Gail, 2007. "CauseSpecific Excess Deaths Associated With Underweight, Overweight, and Obesity.” Journal of the American Medical Association. Vol 298 (17): 2028-37.

Janssen, F., and A.E. Kunst. 2005. Cohort patterns in mortality trends among the elderly in seven European countries 1950-99. International Journal of Epidemiology 2005;34:1149-1159.

Kochanek, K.D., X. Jiaquan, S.L.Murphy, A.M. Minino, and H. Kung. 2011. "Deaths: Final Data for 2009" National Vital Statistics Reports Vol. 60(3). National Center for Health Statistics. Hyattsville, Md. 
Lee, J.M. et al., 2010. "Getting heavier, younger: trajectories of obesity over the life course”. International Journal of Obesity, 34(4), pp.614-23.

Leistikow, B. N., Z. Kabir, G. N. Connolly, L. Clancy and H. R. Alpert. 2008. "Male Tobacco Smoke Load and Non-Lung Cancer Mortality Associations in Massachusetts." BMC Cancer 8:341.

Mehta, N.K. and V.W. Chang. 2009. "Mortality Attributable to Obesity among Middle-Aged Adults in the United States." Demography 46(4):851.

-. 2011. "Secular Declines in the Association between Obesity and Mortality in the United States." Population and Development Review. 37(3) : 435-51.

Mehta, Neil and Samuel Preston. 2012. "Continued Increases in the Relative Risk of Death from Smoking”. American Journal of Public Health. Published online, Feb. 16, 2012.B

Mokdad, A. H., J. S. Marks, D. F. Stroup and J. L. Gerberding. 2004. "Actual Causes of Death in the United States, 2000." Journal of the American Medical Association 291:1238-45.

Mokdad, A. H., J. S. Marks, D. F. Stroup and J. L. Gerberding, 2005. "Correction: Actual Causes of Death in the United States". JAMA 293(3):293-4.

Oza , Shefali, Michael J. Thun , S. Jane Henley ,1, Alan D. Lopez, and Majid Ezzati, 2011 "How many deaths are attributable to smoking in the United States? Comparison of methods for estimating smoking-attributable mortality when smoking prevalence changes." Preventive Medicine 52 (2011) 428-433

Peto, R., A. D. Lopez, J. Boreham, M. Thun and C. Heath Jr. 1992. "Mortality from Tobacco in Developed Countries: Indirect Estimation from National Vital Statistics." Lancet 339:1268-78.

Preston, Samuel, Dana Glei and John Wilmoth. 2011. "Contribution of Smoking to International Differences in Life Expectancy”. Pages 105-131 in International Differences in Mortality at Older Ages: Dimensions and Sources. Eileen Crimmins, Samuel Preston, and Barney Cohen, editors. 2011. National Academy Press. Washington, D.C.

Preston, Samuel and Haidong Wang. 2006. "Changing Sex Differentials in Mortality in the United States: The Role of Cohort Smoking Patterns” Demography Vol. 43(4): 413-34.

Preston, Samuel, Neil Mehta, and Andrew Stokes. 2012. "Modeling Obesity Histories in Cohort Analyses of Health and Mortality" Forthcoming, Epidemiology

Prospective Studies Collaboration. 2009. "Body-mass index and cause-specific mortality in 900,000 adults: collaborative analyses of 57 prospective studies”. Lancet. Vol. 373:108396.

Rostron B. Smoking-attributable Mortality in the United States. Epidemiology. 2011;22(3):350355.

Ruhm, C.J., 2007. “Current and Future Prevalence of Obesity and Severe Obesity in the United States.” NBER Working Paper 13181. Cambridge, Mass.

Soneji, Samir and Gary King. 2012. "Statistical Security for Social Security”. Demography 49: 1037-60.

Stewart, S.T., Cutler, D.M. \& Rosen, A.B., 2009. Forecasting the effects of obesity and smoking on U.S. life expectancy. The New England Journal of Medicine, 361(23): 2252-60. 
Technical Panel to the Social Security Advisory Board. 2011. Technical Panel Report on Assumptions and Methods. Social Security Administration. Washington, D.C.

Thun MJ, and Heath C. 1997. Changes in mortality from smoking in two American Cancer Society prospective studies since 1959. Preventive Medicine. 26(4):422-6.

Thun MJ, et al. 1997."Trends in tobacco smoking and mortality from cigarette use in Cancer Prevention Studies I (1959 through 1965) and II (1982 through 1988)." In: Changes in Cigarette-Related Disease Risks and their Implications for Prevention and Control. Smoking and Tobacco Control Monograph No. 8. NIH Pub No. 97-4213; 1997.

Trustees, Federal Old-Age and Survivors Insurance and Federal Disability Insurance Trust Funds. 2012. Annual Report of the Board of Trustees. Washington, D.C. Government Printing Office.

United States Department of Agriculture. 2007. Tobacco Situation and Outlook Report Yearbook. U.S. Department of Agriculture. Washington, D.C.

United States National Center for Health Statistics. 2012. Underlying Cause of Death 1999-2009. On CDC WONDER Online Database, released 2012. Data for year 2009 are compiled from the Multiple Cause of Death File 2009, Series 20 No. 2O, 2012.

Wang, Haidong and Samuel Preston. 2009. "Forecasting United States Mortality Using Cohort Smoking Histories" Proceedings of the National Academy of Sciences Vol. 106(2): 393-98.

Wang, Y. et al., 2008. "Will all Americans become overweight or obese? Estimating the progression and cost of the US obesity epidemic". Obesity 16(10): 2323-30.

Yamaguchi, Naohito, Yumiko Mchizuki-Kobayashi, and Osuma Utsumomiya, 2000. "Quantitative Relationship between Cumulative Cigarette Consumption and lung cancer mortality in Japan". International Journal of Epidemiology. 29:963-68. 
Fig 1. Trends in Smoking and Obesity in the United States

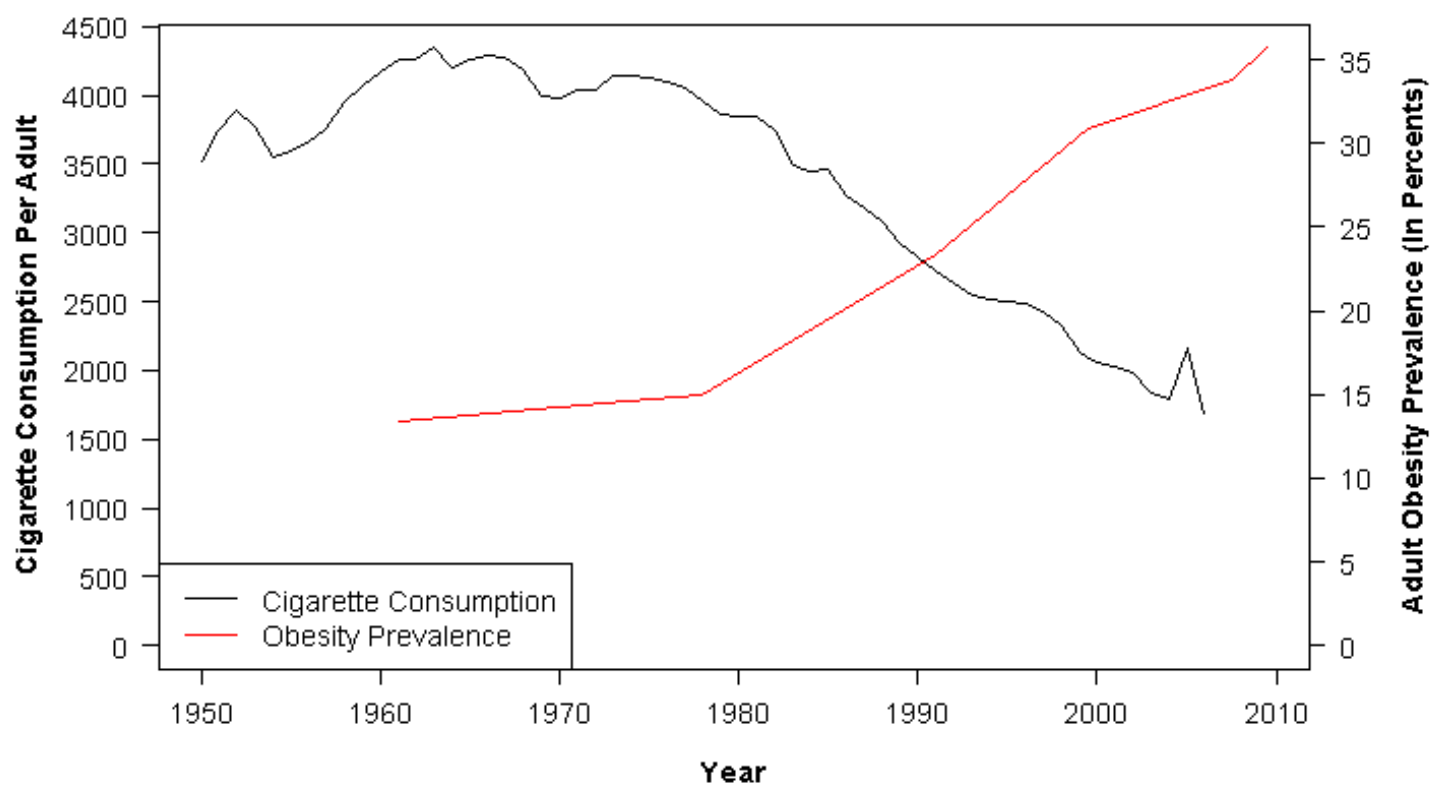

Sources: Cigarette consumption data per adult per year are extracted from Tobacco Situation and Outlook Report Yearbook. U.S. Department of Agriculture, October 2007. Obesity data based on measured body mass index in NHANES from 1960 to 2010. 
Fig 2. Actual and Projected Trends in Body Mass Index

A. Males

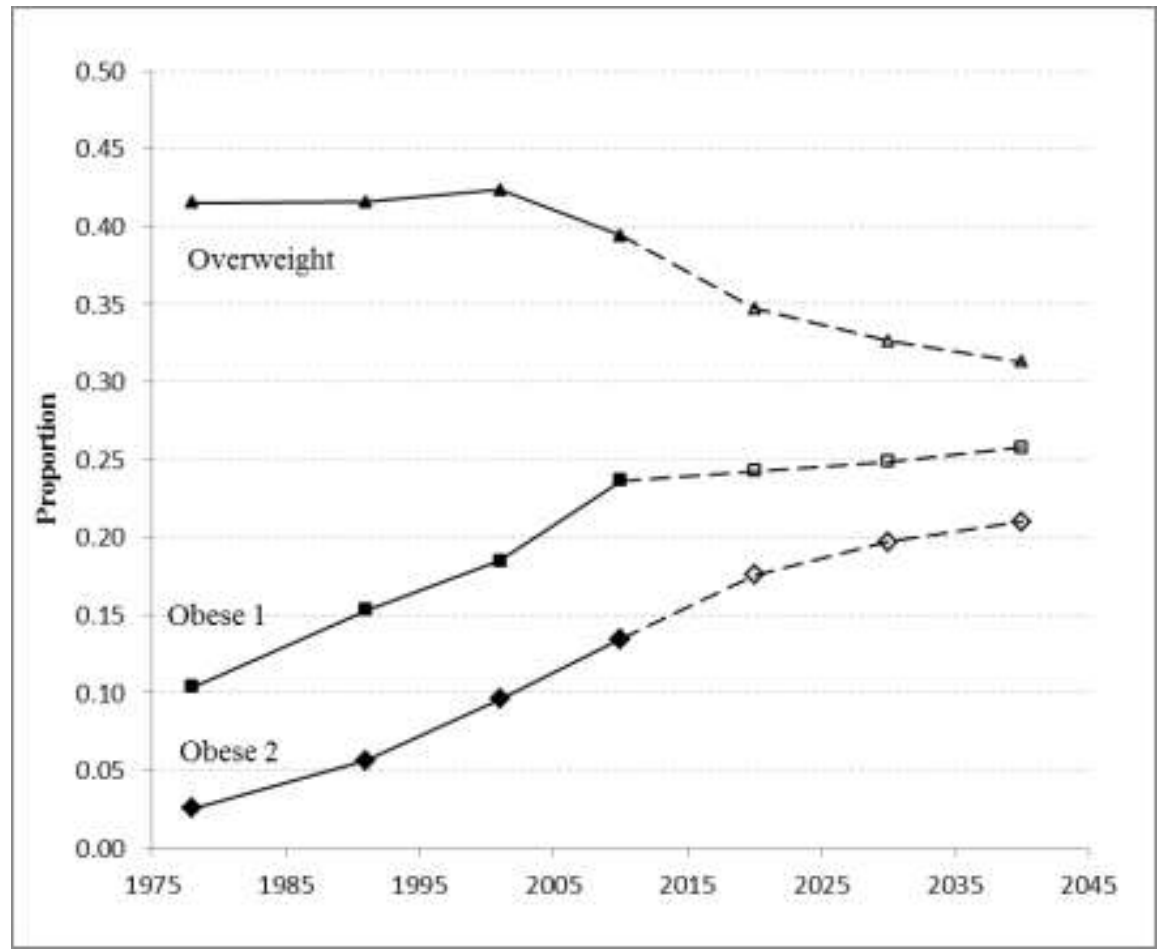

\section{B. Females}

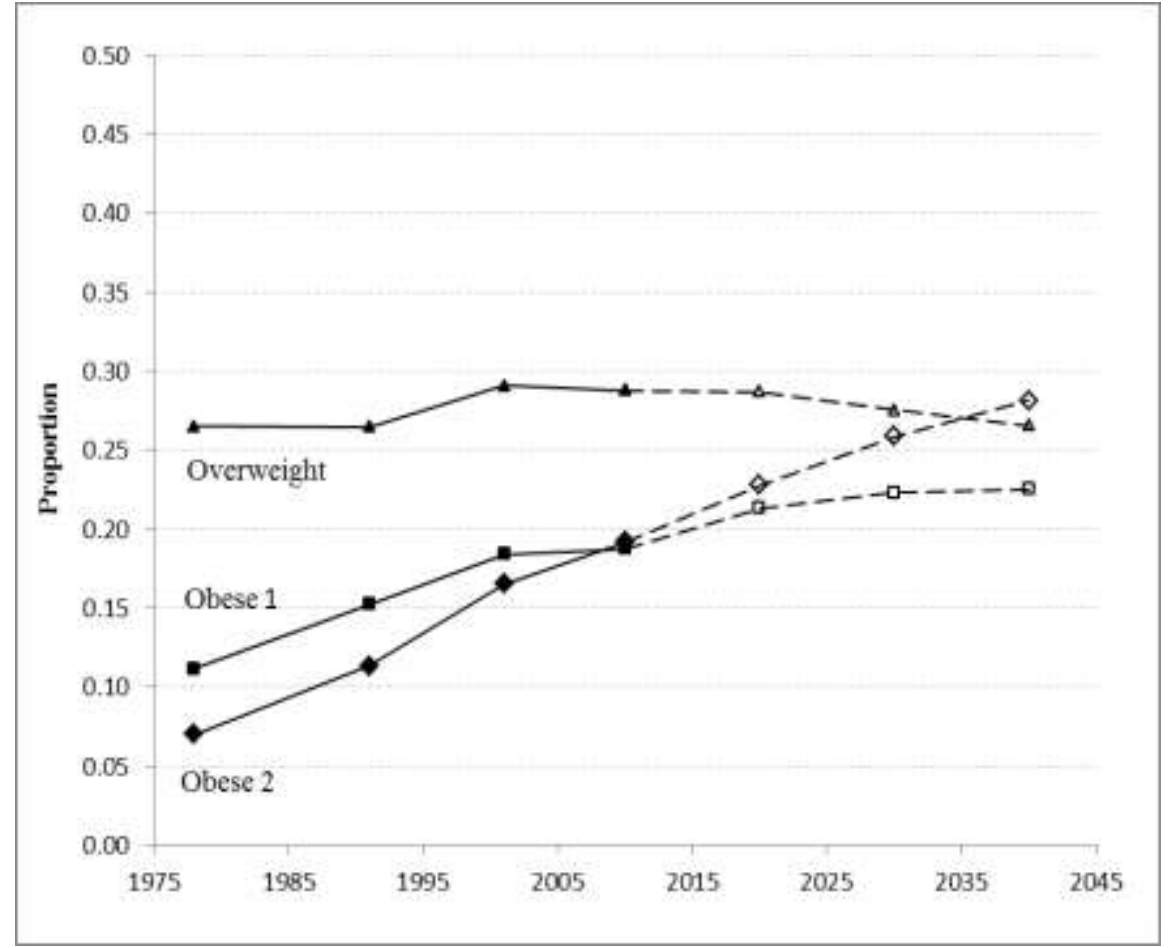


Fig 3. Effects of Projected Trends in Smoking and Body Mass Index on Age-Specific Death Rates

\section{Males}

Females

A. Obesity
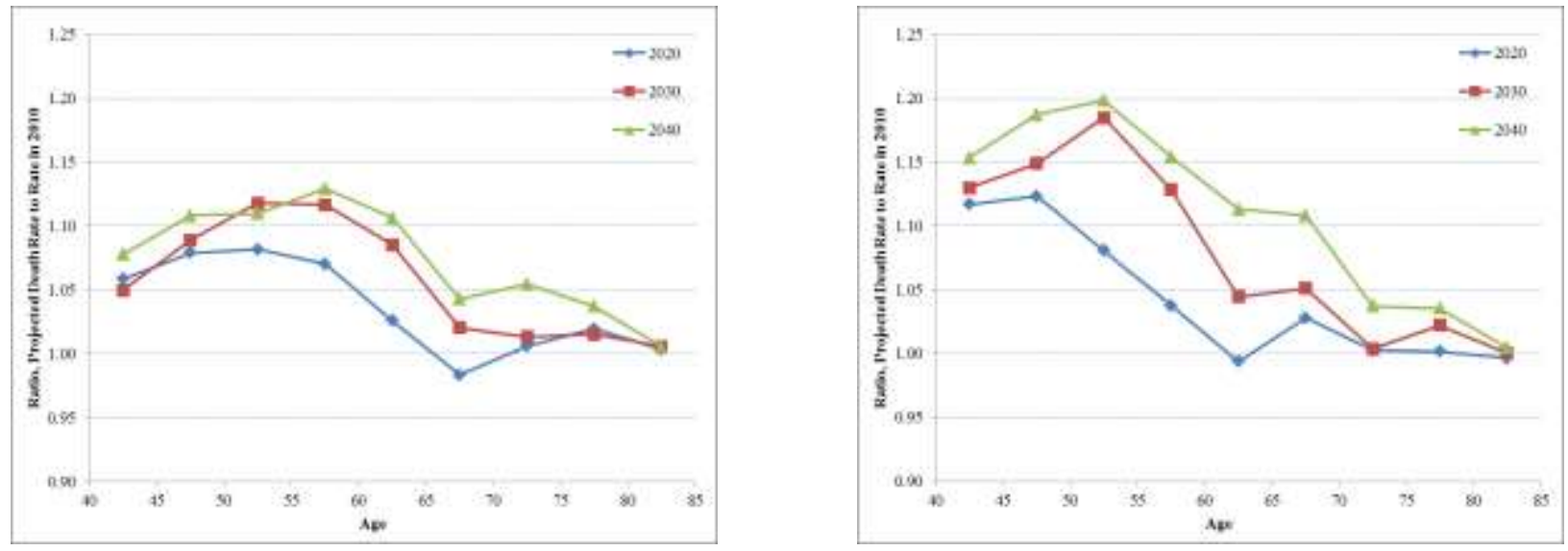

\section{B. Smoking}
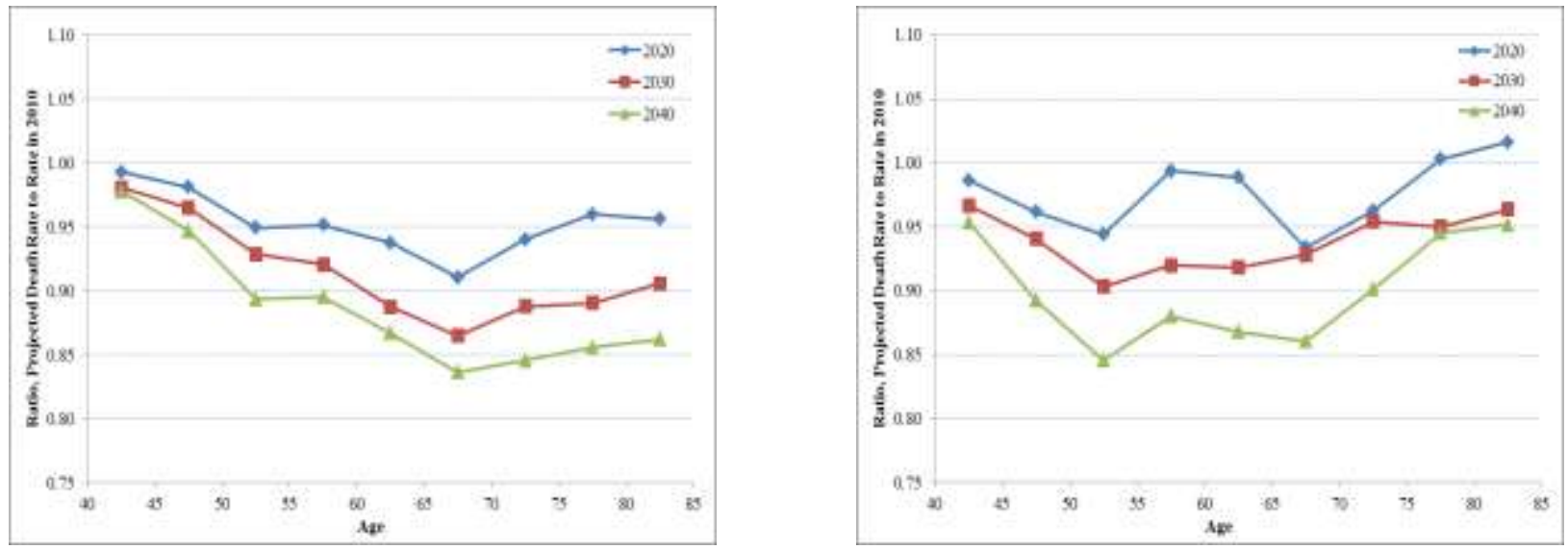
Fig 4. U.S. Lung Cancer Mortality for Males

\section{A. By Cohort}

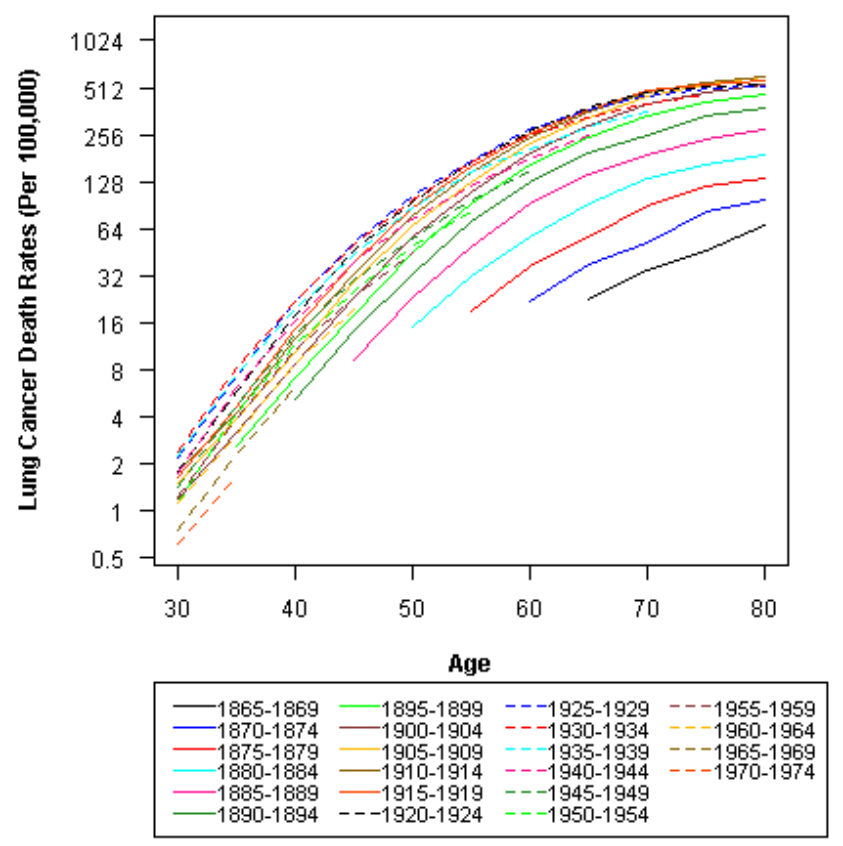

\section{B. By Period}

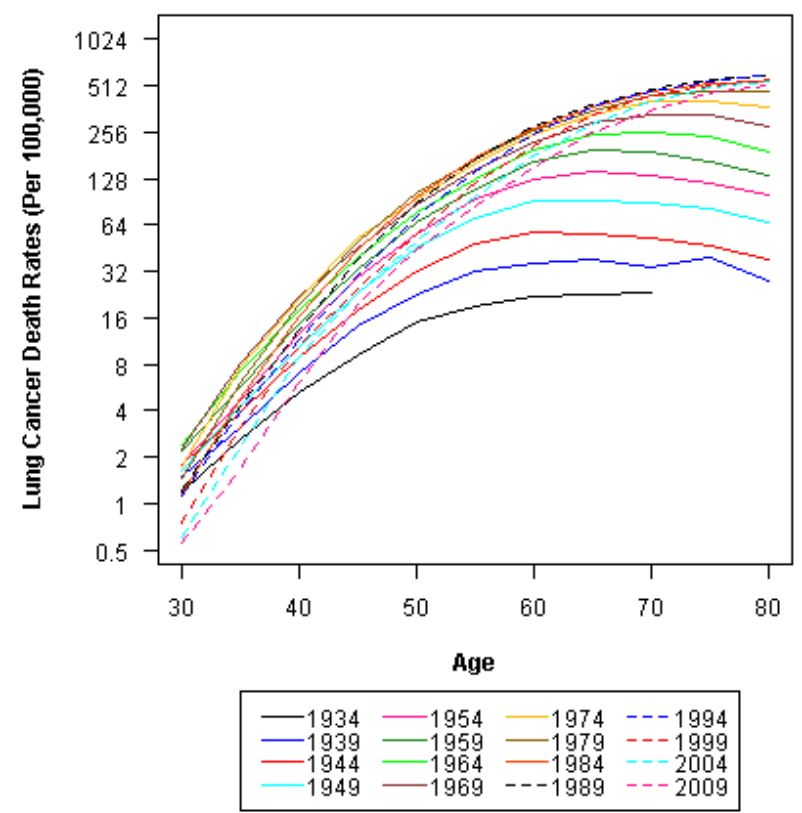


Fig 5. Mean Number of Years Spent as a Cigarette Smoker before Age 40 by Cohort

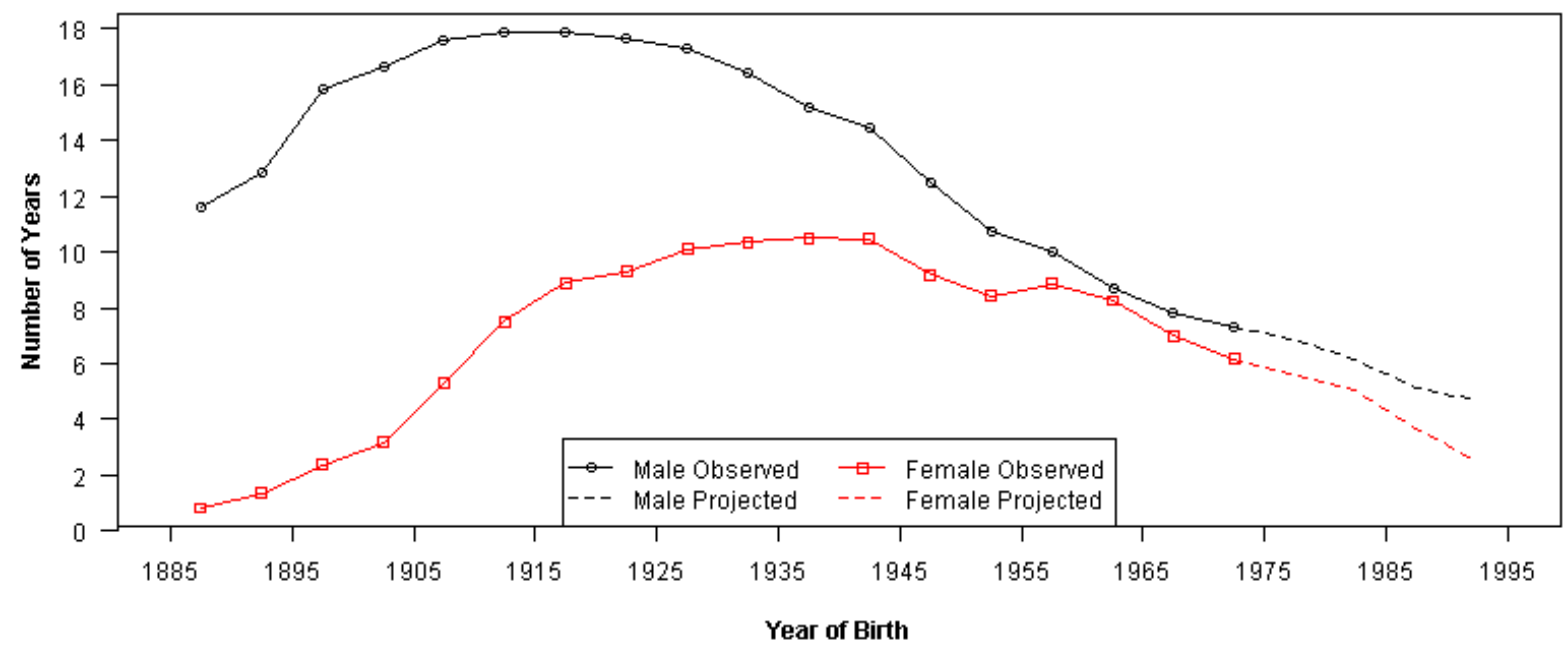


Fig 6. Cohort Coefficients Predicting Lung Cancer Mortality and Cumulative Cohort Smoking by Age 40

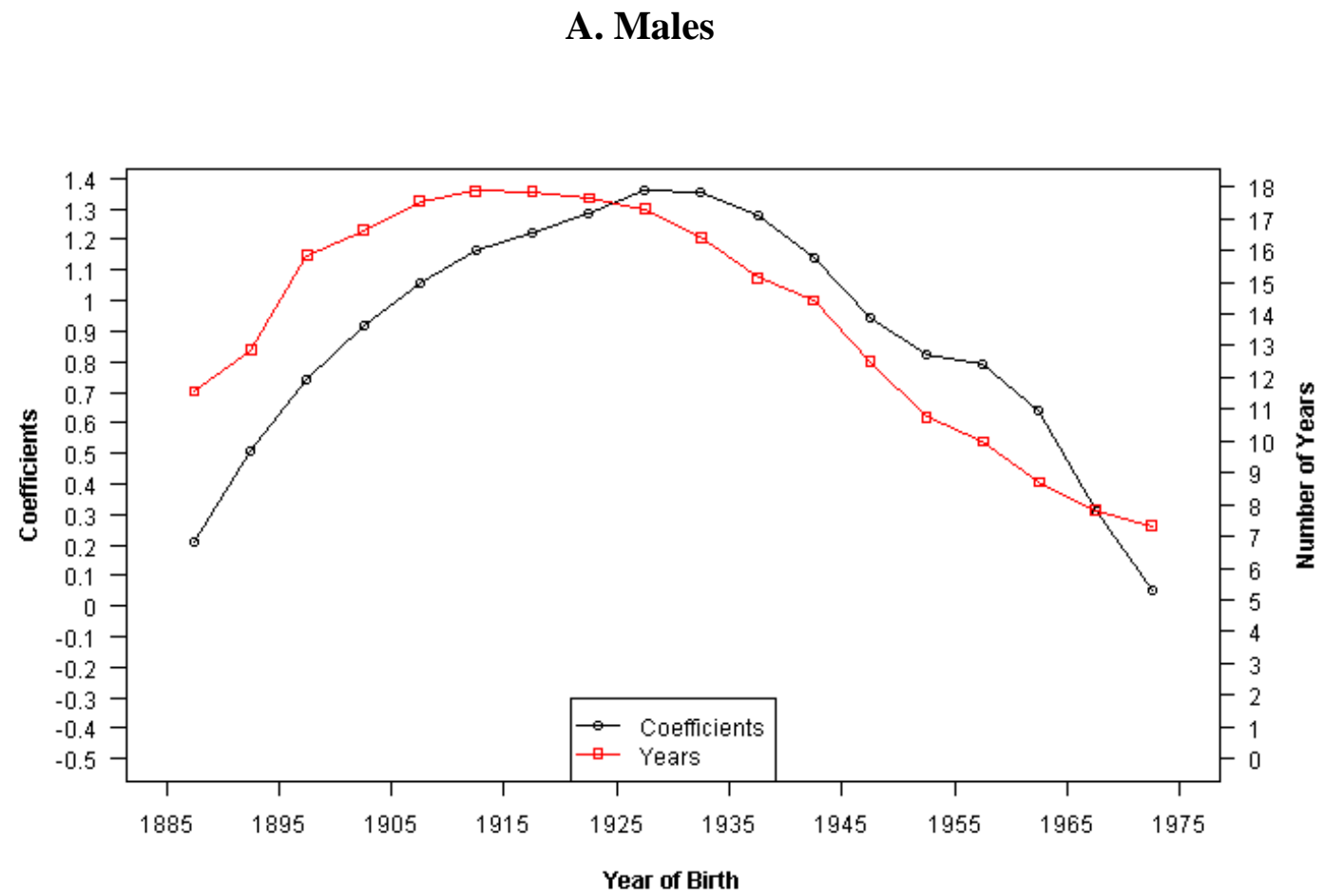

\section{B. Females}

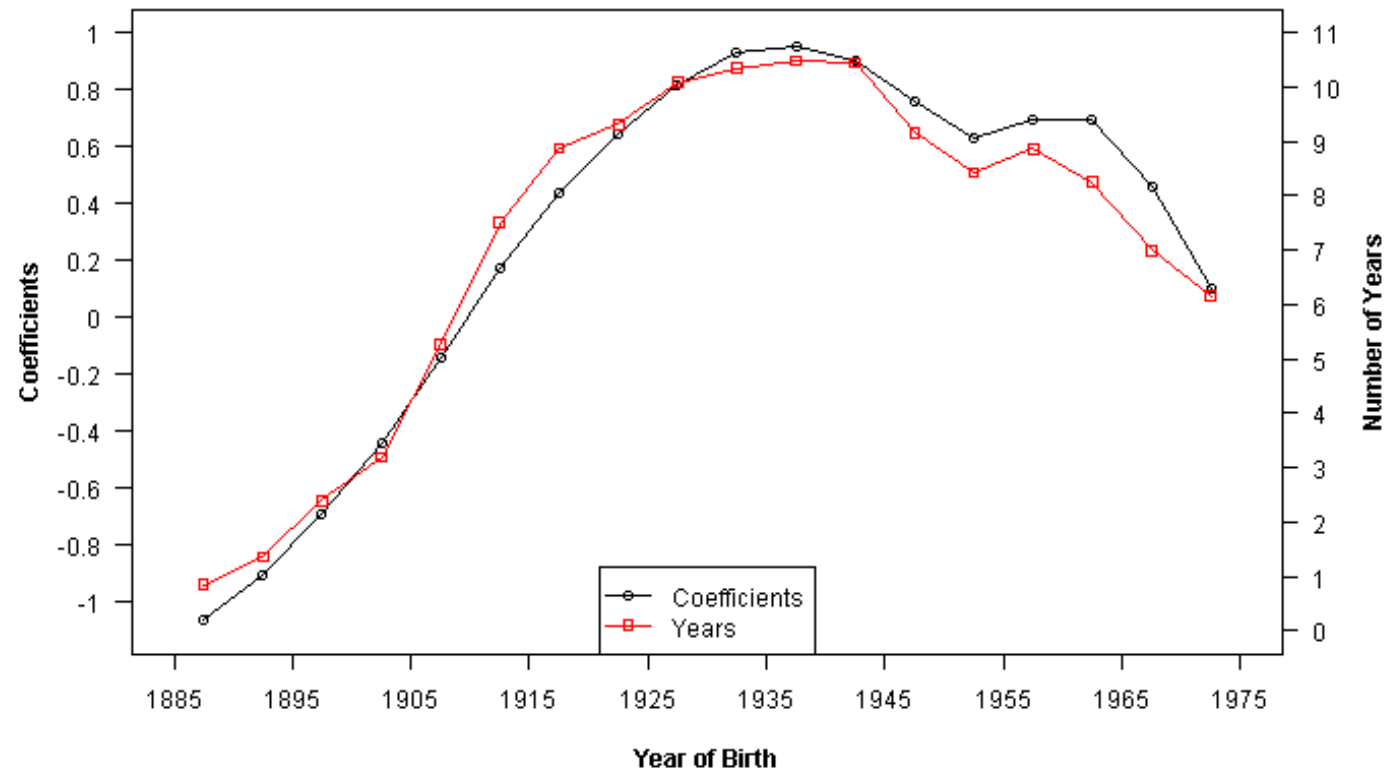


Fig 7. Combined Effects of Projected Trends in Smoking and Body Mass Index on AgeSpecific Death Rates

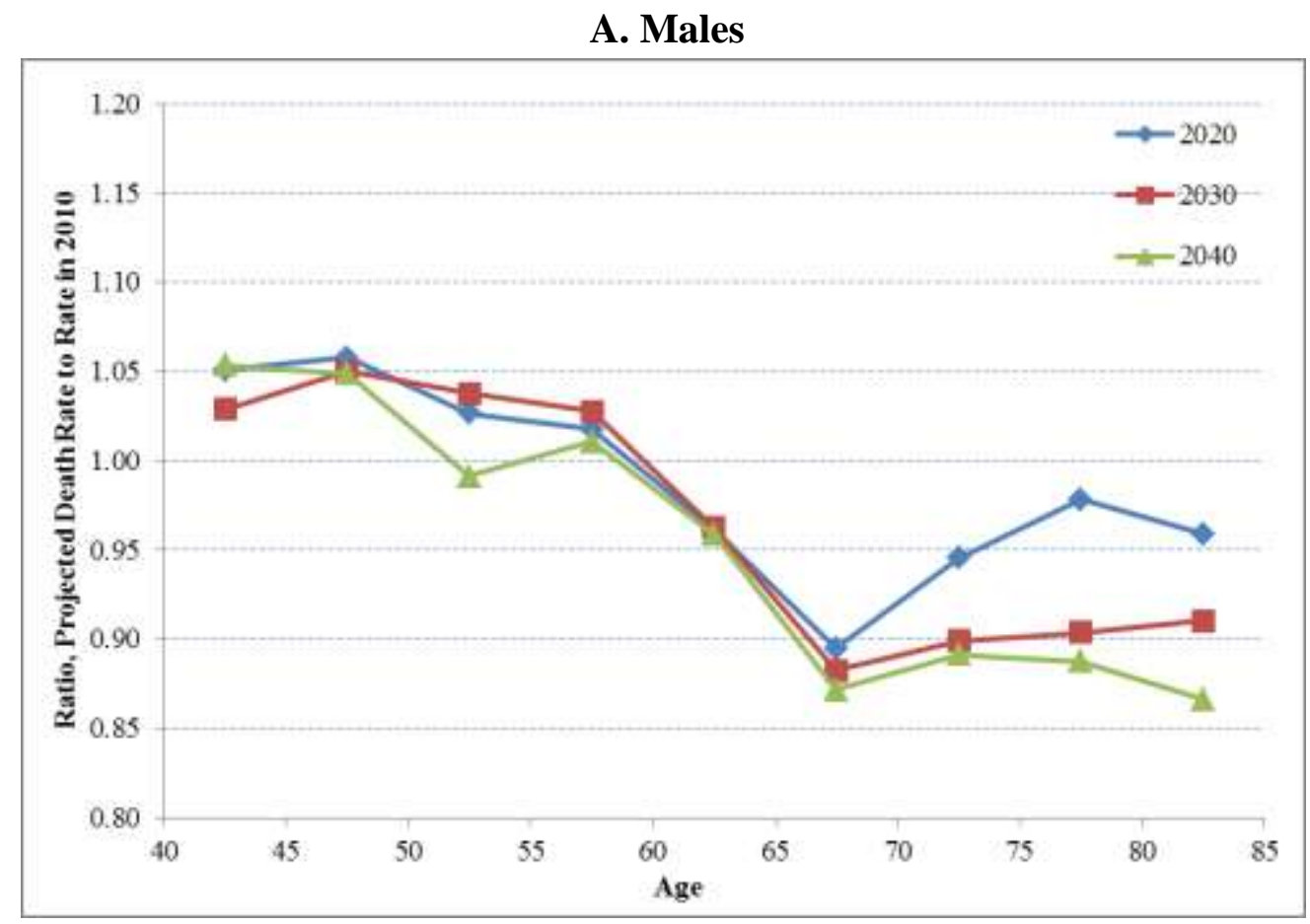

B. Females

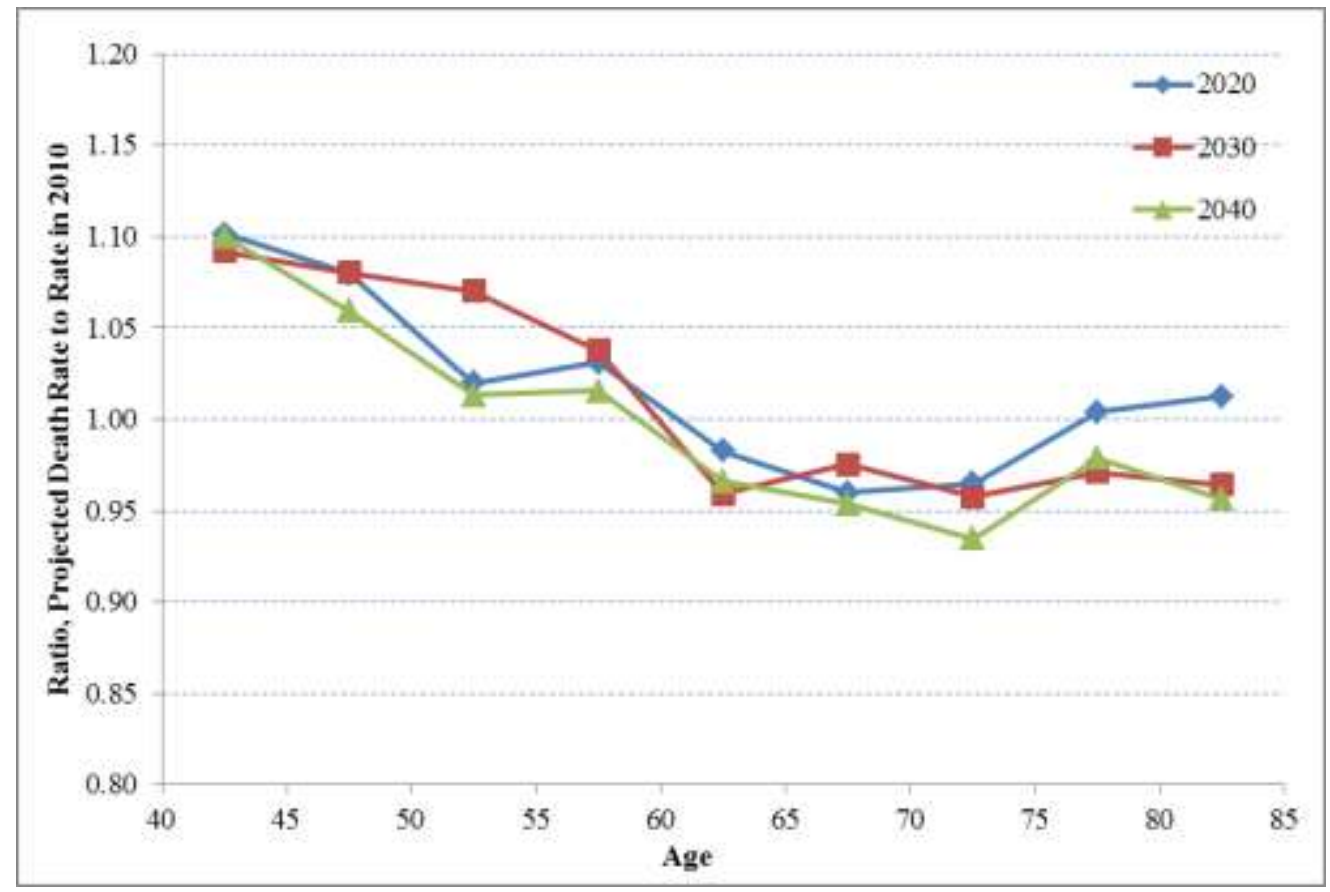




\section{Table 1. Ten-Year BMI Transition Matrices in the United States}

A. Transition probabilities across categories of BMI over three periods (adults ages 25-84) ${ }^{\mathrm{a}}$

\begin{tabular}{|c|c|c|c|c|c|c|c|c|c|c|c|c|}
\hline & \multicolumn{4}{|c|}{ 1980-1990 } & \multicolumn{4}{|c|}{$1990-2000$} & \multicolumn{4}{|c|}{ 1998-2008 } \\
\hline & Normal & Over & Obese 1 & Obese 2 & Normal & Over & Obese 1 & Obese 2 & Normal & Over & Obese 1 & Obese 2 \\
\hline Normal & $\begin{array}{c}0.67 \\
(0.01)\end{array}$ & $\begin{array}{c}0.30 \\
(0.01)\end{array}$ & $\begin{array}{c}0.03 \\
(0.00)\end{array}$ & $\begin{array}{c}0.00 \\
(0.00)\end{array}$ & $\begin{array}{c}0.61 \\
(0.01)\end{array}$ & $\begin{array}{c}0.34 \\
(0.01)\end{array}$ & $\begin{array}{c}0.04 \\
(0.00)\end{array}$ & $\begin{array}{c}0.01 \\
(0.00)\end{array}$ & $\begin{array}{c}0.63 \\
(0.02)\end{array}$ & $\begin{array}{c}0.33 \\
(0.01)\end{array}$ & $\begin{array}{c}0.03 \\
(0.00)\end{array}$ & $\begin{array}{c}0.01 \\
(0.00)\end{array}$ \\
\hline Overweight & $\begin{array}{c}0.12 \\
(0.01)\end{array}$ & $\begin{array}{c}0.52 \\
(0.01)\end{array}$ & $\begin{array}{c}0.29 \\
(0.01)\end{array}$ & $\begin{array}{c}0.08 \\
(0.01)\end{array}$ & $\begin{array}{c}0.10 \\
(0.01)\end{array}$ & $\begin{array}{c}0.48 \\
(0.01)\end{array}$ & $\begin{array}{c}0.32 \\
(0.01)\end{array}$ & $\begin{array}{c}0.10 \\
(0.01)\end{array}$ & $\begin{array}{c}0.09 \\
(0.01)\end{array}$ & $\begin{array}{c}0.51 \\
(0.02)\end{array}$ & $\begin{array}{c}0.31 \\
(0.02)\end{array}$ & $\begin{array}{c}0.09 \\
(0.01)\end{array}$ \\
\hline Obese Class 1 & $\begin{array}{c}0.02 \\
(0.00)\end{array}$ & $\begin{array}{c}0.22 \\
(0.02)\end{array}$ & $\begin{array}{c}0.44 \\
(0.02)\end{array}$ & $\begin{array}{c}0.31 \\
(0.03)\end{array}$ & $\begin{array}{c}0.02 \\
(0.00)\end{array}$ & $\begin{array}{c}0.16 \\
(0.01)\end{array}$ & $\begin{array}{c}0.41 \\
(0.01)\end{array}$ & $\begin{array}{c}0.41 \\
(0.02)\end{array}$ & $\begin{array}{c}0.02 \\
(0.00)\end{array}$ & $\begin{array}{c}0.21 \\
(0.02)\end{array}$ & $\begin{array}{c}0.42 \\
(0.02)\end{array}$ & $\begin{array}{c}0.35 \\
(0.02)\end{array}$ \\
\hline Obese Class 2 & $\begin{array}{c}0.01 \\
(0.00)\end{array}$ & $\begin{array}{c}0.07 \\
(0.01)\end{array}$ & $\begin{array}{c}0.28 \\
(0.02)\end{array}$ & $\begin{array}{c}0.64 \\
(0.03)\end{array}$ & $\begin{array}{c}0.00 \\
(0.00)\end{array}$ & $\begin{array}{c}0.04 \\
(0.01)\end{array}$ & $\begin{array}{c}0.20 \\
(0.03)\end{array}$ & $\begin{array}{c}0.76 \\
(0.04)\end{array}$ & $\begin{array}{c}0.00 \\
(0.00)\end{array}$ & $\begin{array}{c}0.06 \\
(0.01)\end{array}$ & $\begin{array}{c}0.24 \\
(0.03)\end{array}$ & $\begin{array}{c}0.70 \\
(0.04)\end{array}$ \\
\hline
\end{tabular}

B. Differences in transition probabilities (standard errors) across periods (adults ages 25-84)

\begin{tabular}{|c|c|c|c|c|c|c|c|c|}
\hline & \multicolumn{4}{|c|}{$1980-1990$ and $1990-2000$} & \multicolumn{4}{|c|}{$1990-2000$ and 1998-2008 } \\
\hline & Normal & Over & Obese 1 & Obese 2 & Normal & Over & Obese 1 & Obese 2 \\
\hline Normal & $\begin{array}{c}-0.057 * \\
(0.019)\end{array}$ & $\begin{array}{l}0.044^{*} \\
(0.016)\end{array}$ & $\begin{array}{l}0.011^{*} \\
(0.004)\end{array}$ & $\begin{array}{l}0.002^{*} \\
(0.001)\end{array}$ & $\begin{array}{c}0.022 \\
(0.020)\end{array}$ & $\begin{array}{c}-0.011 \\
(0.017)\end{array}$ & $\begin{array}{c}-0.009 * \\
(0.005)\end{array}$ & $\begin{array}{c}-0.001 \\
(0.001)\end{array}$ \\
\hline Overweight & $\begin{array}{c}-0.012 \\
(0.011)\end{array}$ & $\begin{array}{c}-0.040 * \\
(0.017)\end{array}$ & $\begin{array}{c}0.030 \\
(0.015)\end{array}$ & $\begin{array}{l}0.022 * \\
(0.010)\end{array}$ & $\begin{array}{c}-0.010 \\
(0.013)\end{array}$ & $\begin{array}{c}0.029 \\
(0.022)\end{array}$ & $\begin{array}{c}-0.014 \\
(0.021)\end{array}$ & $\begin{array}{c}-0.004 \\
(0.014)\end{array}$ \\
\hline Obese Class 1 & $\begin{array}{l}-0.006 \\
(0.004)\end{array}$ & $\begin{array}{c}-0.061^{*} \\
(0.023)\end{array}$ & $\begin{array}{c}-0.033 \\
(0.019)\end{array}$ & $\begin{array}{l}0.100 * \\
(0.035)\end{array}$ & $\begin{array}{c}0.003 \\
(0.004)\end{array}$ & $\begin{array}{c}0.046 \\
(0.024)\end{array}$ & $\begin{array}{c}0.010 \\
(0.022)\end{array}$ & $\begin{array}{c}-0.059 \\
(0.031)\end{array}$ \\
\hline Obese Class 2 & $\begin{array}{c}-0.002 \\
(0.001)\end{array}$ & $\begin{array}{c}-0.026 * \\
(0.013)\end{array}$ & $\begin{array}{c}-0.089 * \\
(0.035)\end{array}$ & $\begin{array}{l}0.117^{*} \\
(0.047)\end{array}$ & $\begin{array}{c}0.001 \\
(0.001)\end{array}$ & $\begin{array}{c}0.015 \\
(0.014)\end{array}$ & $\begin{array}{c}0.041 \\
(0.039)\end{array}$ & $\begin{array}{c}-0.056 \\
(0.053)\end{array}$ \\
\hline
\end{tabular}

Sources: Transition probabilities for 1980-1990 were estimated using data from the National Health and Nutrition Examination Survey (NHANES) III; those for 1990-2000 and 1998-2008 were estimated using data from NHANES continuous waves 1999-2002 and 2007-2008 respectively.

${ }^{a}$ Transition probabilities across periods were predicted fixing age at its population average in 2007-2008.

$* \mathrm{p}<0.05$ 
Table 2. Sex-Specific Ten-Year BMI Transition Matrices in the United States

Transition probabilities (standard errors) across categories of body mass index and sex (US adults ages 25-84)

\begin{tabular}{lcccc}
\hline & \multicolumn{4}{c}{ Males } \\
\cline { 2 - 5 } Normal & Normal & Over & Obese 1 & Obese 2 \\
\hline \multirow{2}{*}{ Overweight } & 0.62 & 0.34 & 0.04 & 0.01 \\
& $(0.01)$ & $(0.01)$ & $(0.00)$ & $(0.00)$ \\
Obese Class 1 & 0.13 & 0.53 & 0.27 & 0.07 \\
& $(0.01)$ & $(0.01)$ & $(0.01)$ & $(0.00)$ \\
Obese Class 2 & 0.02 & 0.23 & 0.44 & 0.31 \\
& $(0.00)$ & $(0.01)$ & $(0.01)$ & $(0.01)$ \\
& 0.00 & 0.06 & 0.24 & 0.70 \\
& $(0.00)$ & $(0.01)$ & $(0.02)$ & $(0.03)$ \\
\hline
\end{tabular}

\begin{tabular}{cccc}
\hline \multicolumn{4}{c}{ Females } \\
\hline Normal & Over & Obese 1 & Obese 2 \\
\hline 0.60 & 0.35 & 0.04 & 0.01 \\
$(0.01)$ & $(0.01)$ & $(0.00)$ & $(0.00)$ \\
0.07 & 0.44 & 0.37 & 0.13 \\
$(0.01)$ & $(0.01)$ & $(0.01)$ & $(0.01)$ \\
0.02 & 0.16 & 0.41 & 0.40 \\
$(0.00)$ & $(0.01)$ & $(0.01)$ & $(0.02)$ \\
0.00 & 0.05 & 0.22 & 0.73 \\
$(0.00)$ & $(0.01)$ & $(0.02)$ & $(0.02)$ \\
\hline
\end{tabular}

Sources: Transition matrices were developed using combined data from NHANES 1999-2008

* $\mathrm{p}<0.05$ 
Table 3. Changes in Life Expectancy at Age 40 Resulting from Changes in Smoking and Obesity

\begin{tabular}{|c|c|c|c|c|c|c|}
\hline \multirow[b]{3}{*}{ Year } & \multicolumn{2}{|c|}{ Changes in } & \multicolumn{2}{|c|}{ Changes in } & \multirow{2}{*}{\multicolumn{2}{|c|}{$\begin{array}{l}\text { Changes in } \\
\frac{\text { Smoking and }}{\text { Obesity }}\end{array}$}} \\
\hline & \multicolumn{2}{|c|}{ Obesity Alone } & \multicolumn{2}{|c|}{$\underline{\text { Smoking Alone }}$} & & \\
\hline & Males & Females & Males & Females & Males & Females \\
\hline 2015 & & & 0.256 & -0.026 & & \\
\hline 2020 & -0.259 & -0.191 & 0.529 & 0.038 & 0.273 & -0.147 \\
\hline 2025 & & & 0.799 & 0.146 & & \\
\hline 2030 & -0.453 & -0.422 & 1.035 & 0.322 & 0.597 & -0.074 \\
\hline 2035 & & & 1.294 & 0.622 & & \\
\hline 2040 & -0.614 & -0.642 & 1.515 & 0.848 & 0.923 & 0.259 \\
\hline
\end{tabular}


Table 4. Sensitivity of Results to Changes in Procedures

\begin{tabular}{|c|c|c|c|c|c|c|}
\hline \multirow[t]{3}{*}{ Change in Procedure } & \multicolumn{4}{|c|}{ Effect on Life Expectancy at age 40 Relative to Main Projection ${ }^{\mathrm{a}}$} & & \\
\hline & \multicolumn{2}{|c|}{2020} & \multicolumn{2}{|c|}{2030} & \multicolumn{2}{|c|}{2040} \\
\hline & Male & Female & Male & Female & Male & Female \\
\hline $\begin{array}{l}\text { Use of measured data on obesity at } \\
\text { age } 25\end{array}$ & -0.031 & -0.052 & -0.048 & -0.073 & -0.026 & -0.062 \\
\hline $\begin{array}{l}\text { No future growth in obesity among } \\
\text { initial cohorts of } 25-34 \text { year olds }\end{array}$ & 0.000 & 0.000 & 0.004 & 0.008 & 0.028 & 0.040 \\
\hline $\begin{array}{l}\text { Use of mortality rates with no } \\
\text { control except age \& sex }\end{array}$ & 0.015 & 0.012 & 0.029 & 0.026 & 0.049 & 0.054 \\
\hline $\begin{array}{l}\text { Use of mortality rates without } \\
\text { inclusion of BMI at age } 25\end{array}$ & 0.008 & 0.036 & 0.058 & 0.118 & 0.145 & 0.223 \\
\hline $\begin{array}{l}\text { Use of alternative series translating } \\
\text { lung cancer into all-cause mortality }\end{array}$ & -0.067 & 0.012 & -0.173 & -0.107 & -0.322 & -0.360 \\
\hline
\end{tabular}

${ }^{\mathrm{a}} \mathrm{A}$ positive value means that the alternative procedure resulted in a gain in projected life expectancy relative to the main procedure. 


\section{$\underline{\text { Appendix A. Construction and Validation of BMI Transition Matrices }}$}

To construct the BMI transition matrices, we used ordered logistic regressions models to estimate transition probabilities across categories of BMI by age and sex in various decadal periods between 1980 and 2008. Independent variables, which pertain to 10 years prior to the survey, included age, the square of age, sex, BMI indicator variables (overweight, obese class 1 , obese class 2) and interaction terms between each of the BMI indicator variables and age, the square of age and sex. We subsequently used the model parameters to generate a series of predictions for each decadal period. We used bootstrapping to estimate uncertainty intervals for the transition probabilities and differences in transition probabilities between periods.

Our strategy of validation is to begin with the cross-section of measured BMIs at t-10, survive those individuals forward by mortality rates observed in NHANES at various BMI levels, and then apply to the survivors the transition matrix described above for the period t-10 to $\mathrm{t}$. We then compare the predicted BMI distribution at time $\mathrm{t}$ to the actual BMI distribution at time t. The cross-sectional distributions at t-10 and t are based on actual measurements, whereas the retrospective information about individual's BMI 10 years earlier is based on retrospective selfreports. To construct the transition matrix, we have corrected the recalled BMI at t-10 by applying an individual-level correction factor based on the proportionate error between measured and self-reported BMI at baseline (Flegal et al. 1995).

Concordance between predicted and actual distributions of BMI was assessed using root mean-squared error (RMSE) and also by examining the frequency with which predicted values of the proportion of individuals in various BMI categories fell within the $95 \%$ confidence intervals of actual values. We conducted the validation separately for each of three periods: 1980-1990, 1990-2000 and 2000-2010. The transition matrix pertaining to 1997/98 to 2007/08 was used in the latter analysis since no later data were available.

Results are shown in Table A.1. It is clear that the predicted BMI distributions in 1990, 2000 and 2010 closely track the rightward shift in the BMI distribution that occurred over this period in all age-groups. For purposes of assessing the discrepancy between predicted and observed distributions of individuals across categories of age and BMI, the data were organized into three age-groups (35-54, 55-69 and 70-84) and four BMI intervals (normal, overweight, obese 1 and obese 2). RMSE was calculated separately for each of the three prediction periods 
(1990, 2000 and 2010) by comparing values across ages and BMI categories (for a total of 12 values per period). RMSE were 1.81, 2.09 and 1.74 for 1990, 2000 and 2010 respectively. Concordance was also assessed by examining whether predicted values were within the 95\% confidence intervals of observed values. There was a good concordance between the actual and observed proportions using this criterion. For the first of the three outcome years, three of the 12 comparisons of predicted to actual proportions showed a predicted proportion that was outside the 95\% confidence interval of the observed proportion. For the second and third outcome years, only two of the 12 predicted values were outside the $95 \% \mathrm{CI}$ of the observed proportion. We conclude that the retrospective reports on BMI 10 years earlier successfully trace the dynamics of the huge increase in obesity that occurred over a period of three decades. 


\begin{tabular}{|c|c|c|c|c|c|c|c|c|c|c|}
\hline \multirow{3}{*}{$\begin{array}{c}\text { Age } \\
(y)\end{array}$} & \multirow{3}{*}{$\begin{array}{l}\text { BMI Cat. } \\
\left(\mathrm{kg} / \mathrm{m}^{2}\right)\end{array}$} & \multicolumn{3}{|c|}{$1990^{b}$} & \multicolumn{3}{|c|}{$2000^{c}$} & \multicolumn{3}{|c|}{$2010^{d}$} \\
\hline & & \multirow{2}{*}{$\begin{array}{c}\begin{array}{c}\text { Predicted } \\
\text { Value }\end{array} \\
39.01\end{array}$} & \multicolumn{2}{|c|}{ Actual $(95 \% \mathrm{Cl})$} & \multirow{2}{*}{$\begin{array}{c}\begin{array}{c}\text { Predicted } \\
\text { Value }\end{array} \\
30.64\end{array}$} & \multicolumn{2}{|c|}{ Actual $(95 \% \mathrm{Cl})$} & \multirow{2}{*}{$\begin{array}{c}\begin{array}{c}\text { Predicted } \\
\text { Value }\end{array} \\
25.22\end{array}$} & \multicolumn{2}{|c|}{ Actual $(95 \% \mathrm{Cl})$} \\
\hline & & & 40.43 & $(37.60-43.27)$ & & 32.83 & (30.06-35.59) & & 28.39 & $(25.68-31.11)$ \\
\hline & 25 to 30 & 35.50 & 34.30 & $(32.59-36.02)$ & 34.40 & 35.36 & $(33.15-37.56)$ & 34.02 & 34.03 & $(31.50-36.57)$ \\
\hline & 30 to 35 & 16.19 & 15.55 & (13.92-17.19) & 18.77 & 17.65 & (16.09-19.20) & 22.24 & 20.38 & $(18.49-22.27)$ \\
\hline & $>35$ & 9.32 & 9.71 & $(8.00-11.42)$ & 16.14 & 14.17 & $(12.03-16.31)$ & 18.53 & 17.19 & $(15.36-19.02)$ \\
\hline \multirow[t]{4}{*}{$55-69$} & $<25$ & 35.94 & 32.33 & $(29.88-34.79)$ & 27.11 & 26.21 & (23.64-28.78) & 24.98 & 23.13 & (19.91-26.36) \\
\hline & 25 to 30 & 36.57 & 38.12 & (35.29-40.95) & 33.63 & 35.64 & $(32.93-38.36)$ & 33.39 & 35.15 & $(30.73-39.57)$ \\
\hline & 30 to 35 & 17.76 & 20.30 & $(18.37-22.24)$ & 21.44 & 22.69 & $(20.64-24.74)$ & 21.79 & 23.13 & (18.92-27.35) \\
\hline & $>35$ & 9.79 & 9.24 & (7.79-10.70) & 17.85 & 15.45 & $(12.62-18.29)$ & 19.83 & 18.58 & (16.24-20.92) \\
\hline \multirow[t]{4}{*}{$70-84$} & $<25$ & 43.78 & 41.11 & $(38.42-43.80)$ & 32.66 & 32.13 & $(28.93-35.32)$ & 25.51 & 22.93 & (19.32-26.53) \\
\hline & 25 to 30 & 35.43 & 37.91 & $(35.86-39.96)$ & 36.84 & 41.25 & $(37.49-45.00)$ & 35.85 & 36.15 & (30.76-41.55) \\
\hline & 30 to 35 & 14.56 & 14.62 & $(12.56-16.68)$ & 19.51 & 18.69 & $(15.81-21.57)$ & 21.53 & 23.64 & $(20.50-26.78)$ \\
\hline & $>35$ & 6.28 & 6.37 & $(5.11-7.63)$ & 10.93 & 7.94 & $(6.27-9.60)$ & 17.10 & 17.28 & $(13.45-21.10)$ \\
\hline $\mathrm{RMSE}^{\mathrm{a}}$ & & & 1.81 & & & 2.09 & & & 1.74 & \\
\hline
\end{tabular}

${ }^{\mathrm{a}} \mathrm{RMSE}=$ root mean-squared error. This metric was used to assess error in predictions and was calculated within each period by comparing predicted to actual BMI values across age categories.

bSources of data for 1990 prediction: Initial population counts: National Health and Nutrition Examination Survey (NHANES) 2 (1976-1980); life tables: NHANES 2 (1976-1980) with mortality follow-up through 1992; transition probabilities and validation data: NHANES 3 (19881994). Ten-year recall weight was corrected prior to estimating transition probabilities.

'Sources of data for 2000 prediction: Initial population counts: NHANES 3 (1988-1994); life tables: NHANES 3 (1988-1994) with mortality follow-up through 2006; transition probabilities and validation data: NHANES Cts. (1999-2002). Ten-year recall weight was corrected prior to estimating transition probabilities.

${ }^{d}$ Sources of data for 2010 prediction: Initial population counts: NHANES Cts. (1999-2002); life tables: NHANES 3 (1988-1994) and NHANES Cts. (1999-2004) with mortality follow-up through 2006; transition probabilities: NHANES Cts. (2007-2008); validation data: NHANES Cts. (20092010). Ten-year recall weight was corrected prior to estimating transition probabilities. 
Appendix B. Description of Baseline and Sensitivity Analysis for Estimating the Effects of Obesity on Future Mortality and Life Expectancy

Baseline Analysis

The baseline procedure for projecting future distributions of BMI at age 25 for the US population begins with initial population counts in 2005 cross-classified by sex, five-year agegroups between 25-84 and age-25 BMI (using categories normal (BMI $<25 \mathrm{~kg} / \mathrm{m} 2$ ), overweight (BMI 25-30) and obese (BMI > 30)). As the proportions morbidly obese at age 25 in the historical series were low, we did not further differentiate the obese category into obese class I and obese class II. We estimated these counts using data from NHANES continuous waves 2003-2006. BMI at age 25 was ascertained through retrospective report. We begin in 2005 instead of 2010 because recall data were not available in the most recent NHANES continuous wave (2009-2010).

We then apply sex- and age-25 BMI specific life tables to the initial distribution in 2005 in order to survive members of the population forward in five-year increments between 2005 and 2040. This step is designed to account for the effects of differential mortality on the BMI distribution as a cohort ages. We generate the life tables using a discrete hazards model implemented on person-month data. Baseline data for the modeling are drawn from pooled NHANES 3 and NHANES continuous waves 1999-2004. Mortality follow-up data through 2006 are obtained from the National Death Index. Adults aged 25-84 are included in the sample and mortality is modeled as a function of BMI at age 25 using the same categories used above. Also as above, BMI at age 25 is elicited through recall at the time of the survey.

To estimate age-25 BMI distributions for new cohorts of 25-29 year olds during the projection period, we estimate a historical age- 25 series, which we then extrapolate forward. We estimate age-25 BMI distributions for future cohorts of 25-29 year olds, beginning with 25-29 year olds in 2010 (who were age 25 in 2007.5) and ending with 25-29 year olds in 2040 (who were age 25 in 2037.5). To do so, we first estimate age-25 BMI distributions for three-year birth cohorts born between 1960-62 and 1972-1974 (i.e. age-25 cohorts 1985-87 to 1997-1999) on the basis of age-25 recall data in NHANES continuous waves 1999-2008. This estimation involved organizing BMI data by birth cohort by subtracting age from survey year. We grouped birth 
cohorts into three-year intervals to increase sample sizes. Then, we separately regress the proportion overweight and obese on a dummy for male, the logarithm of time (years since 1970) and an interaction between the two terms. Using the parameters of these regressions, we extrapolate the age-25 overweight and obese series forward in five-year increments between 2007.5 and 2037.5 .

In all cases, we used an individual-level correction of the recall data, based on the proportionate error between measured and self-reported current BMI, which were also elicited in the survey. Finally, we apply the parameters of a joint mortality model, which appear in Table B1, to current and age-25 BMI projections to obtain the effects of obesity on future mortality rates.

Sensitivity Analysis 1 - Use of measured data on obesity at age 25

Our first sensitivity analysis uses an alternative procedure for forecasting future distributions of age-25 BMI, which relies on measured rather than retrospectively-reported data on height and weight for deriving age-25 BMI distributions. Measured data on height and weight with which to reconstruct cohort obesity patterns are available periodically since 1960 from NHANES. All the available NHANES data were used to reconstruct the distribution of BMI at age 25 across five-year US birth cohorts between 1935-1937 and 1984-1985 (age 25 in 1960-62 to 2009-2010). BMI distributions at central age 25 (ages 20-29) were calculated in each of the following surveys, taking into account complex survey design: NHES I (1960-1962), NHANES I, NHANES II, NHANES III (disaggregated into Phases I (1988-1991) and II (1991-1994) and NHANES continuous waves 1999-2000, 2001-2002, 2003-2004, 2005-2006, 2007-2008, 20092010. In calculating BMI distributions, we used the same categories as were used in the baseline analysis.

We separately regressed the proportions overweight and obese on an indicator for sex, the logarithm of time (years since 1940) and an interaction between the two terms. Using the parameters from the model, we interpolated the series to obtain proportions overweight and obese for birth cohorts separated by five-year periods (age 25 in 1967.5,..,2007.5). We also extrapolated the series to obtain proportions overweight and obese in later cohorts (age 25 in 2012.5 through 2037.5). We assumed that the proportions obese at age 25 in five-year intervals 
between 1952.5 and 1967.5 were constant at their predicted values in 1967.5. This assumption is supported by the fact that the obese series was essentially flat between NHES I and NHANES I for both males and females. Our estimates for 1952.5 provide us with weight histories for $80-84$ year olds in 2010. We extrapolate forward to 2037.5, as this gives us weight histories for 25-29 year olds in 2040.

The age-25 series developed above provides weight histories for all adults aged 25-84 during the projection interval 2010-2040. However, these are not representative of the BMI distributions at age 25 of surviving adults in the projection interval because of differences in survival rates among BMI classes beyond age 25. Therefore, the next step in the sensitivity analysis is to adjust the age-25 distributions for differential mortality according to BMI-at-age-25 specific mortality rates. We use the sex- and BMI-at-age-25 specific life tables developed in the baseline analysis to survive members of each age-25 cohort to their attained ages in 2010, 2020, 2030 and 2040. These procedures produce age-25 BMI levels, adjusting for differential mortality, for all cohorts aged 25-84 between 2010 and 2040. As in the baseline analysis, to calculate the total effects of obesity (age-25 and baseline BMI levels) on mortality levels in the future, we apply the parameters of a joint mortality model, which appear in Table B1, to the projected baseline and age-25 BMI distributions.

Sensitivity Analysis 2 - No future growth in obesity among initial cohorts of 25-34 year olds

In this sensitivity analysis we follow the same procedure as in the baseline analysis, with the exception that instead of extrapolating recent trends in the BMI distribution at ages 25-34 as well as at age-25, we have assumed that the distributions remain constant at their levels in 2010.

Sensitivity Analysis 3 - Use of mortality rates with no control except age \& sex

In this sensitivity analysis we follow the same procedure as in the baseline analysis, with the exception that we have re-estimated the model parameters in Table B1, omitting adjustments for covariates. The new model parameters appear in Table B2.

Sensitivity Analysis 4 - Use of mortality rates without inclusion of BMI at age 25 
In this sensitivity analysis, we examine the effects of current obesity only. We apply the projected future distributions of current obesity to parameters of a regression model in which terms for age-25 obesity have been omitted. The parameters of this model appear in Table B3.

\section{Table B1. Baseline Model Parameters for Regression Equation Predicting Mortality as a Function of Current Obesity and Obesity at Age 25. Model with covariate adjustment and correction of obesity history data.}

\begin{tabular}{lcccc}
\hline Covariates $^{\mathrm{a}}$ & Coefficients & $\mathrm{SE}$ & $\mathrm{t}$ & $\mathrm{P}>\mathrm{t}$ \\
\hline Female & -0.309 & 0.050 & -6.13 & 0.000 \\
Age & 0.099 & 0.004 & 25.58 & 0.000 \\
Age 25 & & & & \\
$\quad$ Overweight (BMI 25-30) & 0.131 & 0.063 & 2.06 & 0.043 \\
$\quad$ Obese (BMI>30) & 0.309 & 0.106 & 2.91 & 0.005 \\
Baseline & & & & \\
$\quad$ Obese class 1 (BMI 30-35) & 0.355 & 0.339 & 1.05 & 0.299 \\
$\quad$ Obese class 2 (BMI>35) & 0.897 & 0.282 & 3.18 & 0.002 \\
$\quad$ Obese class 1 x Age & -0.008 & 0.009 & -0.87 & 0.385 \\
$\quad$ Obese class 2 x Age & -0.018 & 0.008 & -2.08 & 0.040 \\
Constant & -9.994 & 0.186 & -53.79 & 0.000 \\
\hline
\end{tabular}

Notes: Parameters are estimated using a discrete hazards model implemented on person-month data. Age represents the number of attained years beyond age 35 . Ages 40-84 are included in the analysis. Baseline obesity terms are derived from measured data on height and weight. The first two years of mortality follow-up are excluded. Estimates reflect sample weights and complex survey design. Sample size $=21,734$; person-years of follow-up=2,041,354; No. of deaths=3,006.

Sources: Data are derived from pooled NHANES III (1988-1994) and NHANES 1999-2004 with mortality follow-up in the National Death Index through December 2006.

${ }^{a}$ Additional covariates in the model include race/ethnicity, educational attainment and smoking.

${ }^{b} \mathrm{BMI}$ at age 25 is corrected for misreporting errors. 
Table B2. Sensitivity Analysis Model Parameters for Regression Equation Predicting Mortality as a Function of Current Obesity and Obesity at Age 25. Model implemented without covariate adjustment.

\begin{tabular}{lcccc}
\hline Covariates & Coefficients & SE & $t$ & P $>\mathrm{t}$ \\
\hline Female & -0.396 & 0.049 & -8.12 & 0.000 \\
Age & 0.093 & 0.003 & 28.13 & 0.000 \\
Age 25 & & & & \\
$\quad$ Overweight (BMI 25-30) & 0.122 & 0.060 & 2.06 & 0.043 \\
$\quad$ Obese (BMI>30) & 0.311 & 0.108 & 2.89 & 0.005 \\
Baseline & & & & \\
$\quad$ Obese class 1 (BMI 30-35) & 0.318 & 0.322 & 0.98 & 0.328 \\
$\quad$ Obese class 2 (BMI>35) & 0.812 & 0.291 & 2.79 & 0.007 \\
$\quad$ Obese class 1 x Age & -0.007 & 0.008 & -0.89 & 0.375 \\
$\quad$ Obese class 2 x Age & -0.016 & 0.009 & -1.83 & 0.071 \\
Constant & -9.480 & 0.131 & -72.64 & 0.000 \\
\hline
\end{tabular}

Notes: See Table B1.

Sources: See Table B1.

${ }^{\mathrm{a}} \mathrm{BMI}$ at age 25 is corrected for misreporting errors.

Table B3. Sensitivity Analysis Model Parameters for Regression Equation Predicting Mortality as a Function of Current Obesity Only.

\begin{tabular}{lcccc}
\hline Covariates $^{\mathrm{a}}$ & Coefficients & $\mathrm{SE}$ & $\mathrm{t}$ & $\mathrm{P}>\mathrm{t}$ \\
\hline Female & -0.337 & 0.049 & -6.88 & 0.000 \\
Age & 0.099 & 0.004 & 25.60 & 0.000 \\
Baseline & & & & \\
$\quad$ Obese class 1 (BMI 30- & & & & \\
35) & 0.445 & 0.341 & 1.31 & 0.195 \\
$\quad$ Obese class 2 (BMI>35) & 1.085 & 0.298 & 3.64 & 0.000 \\
$\quad$ Obese class 1 x Age & -0.009 & 0.009 & -1.00 & 0.320 \\
$\quad$ Obese class 2 x Age & -0.020 & 0.009 & -2.28 & 0.025 \\
Constant & -9.954 & 0.185 & -53.82 & 0.000 \\
\hline
\end{tabular}

Notes: See Table B1.

Sources: See Table B1.

${ }^{a}$ Additional covariates in the model include race/ethnicity, educational attainment and smoking. 


\section{$\underline{\text { Appendix C. Construction of Life Tables }}$}

The most common summary measure of age-specific mortality rates is life expectancy, an indicator of how many additional years someone is expected to live after reaching a particular age. Life tables are required in order to estimate life expectancy. The baseline life table that we use for comparison purposes is that for the United States in 2009, which we assume to apply to 2010. The National Center for Health Statistics has not published life tables for 2009 but has provided several preliminary estimates of life expectancy at various ages (Kochanek et al. 2011) We use their value of life expectancy at age 85 and construct our own life table values for ages 40-84 based on age-specific death rates for both sexes in 5-year age intervals that have been released electronically (US National Center for Health Statistics 2012). Our constructed life table has a value of life expectancy at age 40 that is within 0.3 years of the preliminary value published by NCHS (Kochanek et al. 2011: Table 6). To this baseline life table we apply the projected proportionate changes in age-specific death rates under various scenarios and recalculate the life table in order to estimate the effects of impending changes in smoking and obesity histories.

We did not estimate the effects of either smoking or obesity on mortality at ages $85+$. In the case of obesity, we assume that there is no effect of BMI on mortality above age 85. The $\mathrm{BMI} /$ age interaction terms shown in the regression equations of Appendix B produce a negative risk of being either Obese I or Obese II-III by age 87.5. So this assumption seems justifiable. In the case of smoking, we assume that the coefficients of cohort smoking histories estimated on data for ages $40-84$ is applicable at ages $85+$. The value of the age coefficient at ages $85+$ is set at its value for ages 80-84, reflecting the leveling off of age effects in lung cancer at advanced ages. 